\title{
Experimental analysis of local void fractions measurements for boiling hydrocarbons in complex geometry
}

\author{
L. Aprin ${ }^{a^{*}}$, P. Mercier ${ }^{b}$, L. Tadrist ${ }^{\mathrm{c}}$ \\ ${ }^{a}$ Laboratoire L.G.E.I., Equipe Risques Industriels et Naturels, Ecole des Mines d'Alès, 6 avenue de \\ Clavières, 30319 Alès cedex, France. \\ ${ }^{\mathrm{b}}$ Laboratoire GREThE CEA/Grenoble, 17 rue des Martyrs, 38054 Grenoble cedex 9, France. \\ ${ }^{\mathrm{c}}$ Laboratoire I.U.S.T.I., Ecole Polytechnique Universitaire de Marseille, Technopôle de Château- \\ Gombert, 5, rue Enrico Fermi, 13453, Marseille, France.
}

\begin{abstract}
The present paper is part of a research program on two-phase flows and heat transfer studies in tube bundles. An experimental study was carried out to analyse the void fraction for vertical two-phase flows. Boiling across a horizontal tube bundle for three hydrocarbons (n-pentane, propane and iso-butane) under saturated conditions is investigated. The experiments were performed on a tube bundle with 45 plain copper tubes of $19.05 \mathrm{~mm}$ outside diameter in a staggered configuration with a pitch to diameter ratio of 1.33. An optical probe has been developed to determine the local void fraction at the minimum cross section between the tubes.

The void fraction for the three hydrocarbons was found to be significantly less than the homogeneous prediction, and correlated well with the Zuber and Findlay (1965) model. A statistical analysis using Probability Density Functions (PDF) was performed to characterise the flow regimes. Two different flow regimes have been identified in the bundle, namely a "bubbly" and an "annular-dispersed" flow. A transition zone was evidenced by analysing the bubble size distribution. A comparison with the only preexisting map, established for adiabatic air-water flow, shows that the transitions between the flow regimes do not correspond to our results in boiling case.
\end{abstract}

Keywords: boiling flow, hydrocarbons, tube bundle, void fraction, flow map, statistical analysis.

* Corresponding author; Tel.: +3346678 27 58; fax: +3346678 2701 .

E-mail address : Laurent.Aprin@ema.fr. 


\section{Introduction and literature survey}

The process industry using heat exchangers with a fluid evaporating across a tube bundle, are numerous. These exchangers like kettle reboilers, flooded evaporators or steam generators are widely used in chemical industries and in nuclear power plants. The design of such equipment is not always adapted to the phenomenology of the two-phase flow in the tube bundle, and the currently used correlations do not take into account all the complexity of this problem (Webb et al. (1994)). Existing models are limited to some given cases of bundle geometries and working fluid with moderate to high mass velocities (mainly refrigerants and adiabatic air-water flow, Jensen et al. (1993), King et al. (1995) and Rahman et al. (1996)). This lack of data for industrial equipment at typical operating conditions results in an increase in the safety margins, and hence an over-sizing of the heat exchangers. Finally, to improve the energy effectiveness of such equipment requires a better understanding of the two-phase flow across the tube bundle. Obtaining a precise flow regime map for boiling flows in tube bundles is thus essential to optimise the heat transfer design and to predict the two-phase flow-induced vibrational phenomena.

\subsection{Two-phase flow patterns inside tubes}

Boiling flows are more complex than single phase flows thus a more detailed analysis is necessary to understand the heat transfer mechanisms and to build predictive methods. Heat transfer under boiling conditions depends strongly on several parameters: the temperature difference between the wall and the fluid, the fluid properties and the wall geometry. It has been shown that for boiling two-phase flow in tubes, the knowledge of flow regimes is key to predicting the pressure and heat transfer (Hewitt and Taylor (1970). The purpose is not to summarise all the studies realised in the past but rather to show the detection flow methods and the complexity of flows in the vertical tube case.

A two dimensional representation is generally used for a flow map. The coordinate system changes according to the authors and there is currently no agreement on the best system. The first flow pattern was proposed by Baker (1954) who defined by visual observations the transitions based on the superficial gas and liquid velocitiesFlow patterns such as bubble, slug, annular and spray were observed. A significant change in flow mechanisms in a large pipe was suggested since the pressure drops were less than those predicted by the Lockhart-Martinelli's correlation (1949). Hewitt and Roberts' map (1969) is the most widely used flow map for air-water and steam-water flows. Bennet et al. (1965) steam-water results were also represented in the Hewitt and Roberts' flow regime map. They performed experiments with steam- 
water mixtures flowing in a pipe. Taitel and Dukler (1977) compared the Hewitt and Roberts' technique to the Govier and Aziz method (1972) and also to Oshinowo and Charles (1974). These comparisons revealed large discrepancies in the general trends of the transitions between flow regimes. These differences can be explained by the "subjective" definitions of the flow regimes and the single representation for several transitions. In order to identify two-phase flow regimes in an objective manner, Zuber and Jones (1975) performed a statistical analysis of X-ray void fraction measurements for vertical air-water flow in a narrow rectangular channel. The Probability Density Functions (PDF) of void fraction fluctuations was successfully used to identify the bubbly, slug and annular flow regimes. Zürcher et al. (2002) and Thome et al. (2003) performed two-phase flow pattern map for evaporation in tubes.

In summary, it appears that even for a simple geometrical configuration, the precise determination of flow regimes is very complex. Most of the proposed flow maps are specific because they are based on visual observations and/or under specific adiabatic conditions. Only Zuber and Jones (1975) have used a quantitative method to identify flow patterns. The theoretical approach of Taitel and Dukler (1977) for flow regime transitions is original; nevertheless this approach is difficult to extrapolate for complex geometries and flows.

\subsection{Two-phase flow patterns in tube bundle}

The main difficulty in the thermal design of horizontal reboilers is the determination of the heat transfer coefficient on the external side tube. The distribution of heat transfer coefficients presents a strong variation according to the position in the bundle (Cornwell et al. (1980)). In order to improve and optimise such equipments more information on two phase flow distribution in tube bundles are needed. Only few experimental studies deal with vertical two-phase flow across a tube bundle. These investigations are based on visual observations because measurements are difficult to develop.

Grant and Murray (1972) were the first to describe the flow pattern in a tube bundle. They used a segmentally baffled transparent heat-exchanger of rectangular cross section with 39 unheated tubes of 19 $\mathrm{mm}$ outer diameter. Tubes were arranged in a staggered configuration of an equilateral triangular orientation $(p / d=1.25)$. They performed their investigations with vertical adiabatic air-water flow. Three flow patterns were visualised: bubbly, intermittent and dispersed flows. A flow regime map was proposed by Grant and Murray based on dimensionless superficial velocities given by Bell et al. (1970).

Kondo and Nakajima (1980) have studied vertical adiabatic air-water flow in three different staggered tube bundles. A quick-closing valves technique was used to measure averaged void fractions. Visual 
observations were performed with high speed video camera for a better identification of flow regimes. They observed bubbly, slug, froth and spray flows. They also provide information on bubble sizes and frequencies, and observed flow patterns dependant only on the air mass flow and the pitch to diameter ratio $(p / d)$. Ulbrich and Mewes (1994) carried out an experimental investigation of air and water flow across a tube bundle with 10 rows of 5 tubes with $20 \mathrm{~mm}$ outside diameter. The tubes were arranged in a square in-line layout with a $1.5 \mathrm{p} / \mathrm{d}$ ratio. The mean void fraction was measured by using a conductivity method. Flow regimes were determined by a combination of visual observations using both a video camera and observing the pressure drop fluctuations between the second and the ninth rows. Three flow patterns were identified (bubbly, intermittent and dispersed flows) and a flow map based on gas and liquid superficial velocities was proposed. Noghrehkar et al. (1999) recently studied a vertical air-water flow across a tube bundle. Experiments were conducted using staggered and in-line tube bundles with the same pitch-to-diameter ratio $(p / d=1.47)$. A resistivity probe was used to access the local void fraction. A probability density function (PDF) of void fraction fluctuations was used as an objective statistical method to determine three different flow regimes (bubbly, intermittent and annular flow) and the associated transitions. A flow regime map was proposed for each bundle. Similar results were observed for the two geometries. However, for the staggered arrangement the bubbly-intermittent transition occurs at higher gas flow rates.

The only study in boiling conditions was reported by Hahne et al. (1990). R-11 refrigerant fluid was used and experiments were carried out with low-finned tubes arranged in staggered and in-line configurations. The authors performed local void fraction measurements with an optical probe. Probability density histograms were realised to identify flow patterns for in-line tube bundles. A bubbly flow regime was mainly observed in the bundle, and a slug flow regime was only detected at the bundle exit. The authors suggest that the combination of a narrow gap and fins may divide large vapour slugs into smaller ones.

\subsection{Void fraction model in tube bundle}

The knowledge of void fraction, and gas and liquid velocities are fundamental in the prediction of the thermal hydraulic characteristics in reboilers (Gebbie and Jensen (1996)). Several authors used a void fraction parameter in their heat transfer correlations for tube bundles (Leong and Cornwell (1979), Polley et al. (1980), Palen and Yang (1983) or Whalley and Butterworth (1983)). All these approaches were limited because of the lack of existing suitable void fraction models.

Kondo and Nakajima (1980) performed void fraction measurements in vertical air-water upflow. Their experiments were realised at low mass velocities $\left(m_{L}<5 \mathrm{~kg} \cdot \mathrm{m}^{-2} \cdot \mathrm{s}^{-1}\right)$. They found that the void fraction 
depends only on the superficial gas velocity. Schrage et al. (1988) carried out experiments for adiabatic air-water flow using quick-closing valves. They measured the mean void fraction for an in-line plain tube bundle arranged in square layout. The authors proposed a new void fraction correlation based upon the Froude number.

Dowlati et al. (1990, 1992a, 1992b, 1993, 1996) measured the void fraction using a gamma densitometry technique for air-water and R-113 refrigerant flow with in-line and staggered tube bundles. As in Schrage's experiments, a higher void fraction is obtained when the total mass flux is increased at fixed qualities. The authors mentioned that the homogeneous model over predicts the experimental data. A void fraction correlation based on Zuber and Findlay's (1965) drift flux model was proposed. This model was independent of the pitch-to-diameter ratio. The Zuber and Findlay's parameters obtained for air-water flow differ from those of R-113 flows. Roser (1999) performed void fraction measurements using an optical probe for $n$-pentane boiling flow in a staggered tube bundle. A large discrepancy between the measured values and the homogeneous model was also observed. The Zuber and Findlay's parameters were deduced by fitting the experimental data. More recently, Feenstra et al. (2000) proposed a void fraction model for upward cross-flow through a horizontal tube bundle with the use of the two phase velocities. Consolini et al. [2006] used this correlation for pressure drop prediction, and found good performances with their results.

The literature survey clearly shows a lack of comprehensive analysis of flow regimes. The majority of investigations were performed with adiabatic two-phase flows. This situation could be rather different in boiling conditions. In fact, the thermohydraulic parameters vary throughout the tubes bundle and the vapour is produced on the surface tubes which is not encountered in adiabatic flows. Understanding the behaviour of two-phase flows under boiling conditions in complex geometries, cannot be done successfully by just a visual approach, or a global parameter analysis alone.

\subsection{Strategy of the present analysis}

In boiling conditions all parameters vary along the tube bundle. For a better understanding of the twophase flow mechanisms, local measurements of parameters are required.

Local flow parameters, such as the vapour and liquid velocities, the mass quality and the void fraction vary along the tube bundle. Hence, the use of local and precise instrumentation is necessary. The lack of experimental studies on the local void fraction in a tube bundle shows the weaknesses and the limits of the previous investigations. The majority of investigations were performed with adiabatic two-phase 
flows and the heat transfer mechanisms were not tackled. Hahne et al. (1990) used boiling conditions only for R-11 refrigerant. Physical properties play an important role in the thermal hydraulic performance of two-phase flows. Consequently Hahne's results are limited and cannot be directly applied to actual fluids used in the process industry.

The objectives of this work are to characterise the two-phase flow patterns outside horizontal tube bundles, to establish original flow maps and finally, to propose an interpretation of the transitions found between flow regimes. The present work is realised with three hydrocarbons $n$-pentane, propane and isobutane, at different working conditions (Table 2), leading to large variations in the physical properties (Table 1). An original data bank is gathered. This will be used for the analysis of the two-phase flow and the heat transfer in tube bundles. This paper focuses on the local void fraction behaviour to determine flow regimes, and to propose a flow map under boiling conditions. The analysis is based on local void fraction measurements. An optical probe system was chosen because of its simplicity, its precision and its compatibility with hydrocarbon fluids. The local void fraction measurement was performed at a central position in the tube bundle. To observe all the possible flow regimes at this unique position, several mass flow velocities and heat flux were investigated.

\section{Experimental set-up and procedure}

\subsection{The test loop}

The hydrocarbon closed loop composes; a test section, a condenser, a cooler and a liquid pump (Figure 1). The test section is representative of an industrial reboiler, but differs by the presence of two vertical walls confining the flow. Half round solid tubes are stuck on the inner walls to prevent flow bypasses. This device avoids internal shell-side re-circulations and allows a precise control of the total mass flow rate through the bundle. The hydrocarbon is pumped from the shell, then subcooled and re-enters the test section at saturated conditions. The hydrocarbon mass flow rate $M_{2 L}$ is controlled by a variable speed pump PM201 up to $1 \mathrm{~kg} . \mathrm{s}^{-1}$. The vapour leaving the boiler at the top is condensed, and returned to the shell where it mixes with the liquid pouring over the wall (Figure 1). The vapour mass flow rate $M_{2 G}$ produced in the bundle is measured downstream of the condenser. Liquid and vapour flow rates are measured by flowmeters allowing determination of the vapour quality at the test section exit. For each experiment, we compared the vapour quality at the test section exit measured at the condenser to the values obtained by heat balance on the hot side. The maximum deviations for these two values do not 
exceed $5 \%$. This procedure was applied systematically for checking the validity of our measurements. This configuration reduces the two-phase flow instabilities, allowing the loop to run at low mass fluxes, which are typical operating conditions for industrial reboilers. Most equipment operates in natural convection (or "thermosiphon") mode, rather than in forced convection as considered in the present work. The present experiments use forced convection because it eliminates circulation instabilities (if the circulation rate is higher than would be achieved by thermosiphon action) and allows to precisely calculating the quality of the two phase flow. The bundle is arranged in a staggered layout with a pitch-todiameter ratio $(p / d=1.33)$. The tubes are $500 \mathrm{~mm}$ long with an inner diameter of $15.7 \mathrm{~mm}$ and an outer diameter of $19.05 \mathrm{~mm}$. All of the copper tubes have been polished on the outer surface with an average roughness of $0.4 \mu \mathrm{m}$.

To produce vapour, hot water-glycol flows inside the tubes. Nine groups of tubes (a control volume) are fed at the same mass flow rate and inlet temperature conditions (Figure 2a). A heat balance is performed for each control volume using the measurement of water-glycol solution mass flow rate $M_{l}$ and the inlet and outlet temperatures $\left(T_{\text {lin }}(j), T_{\text {lout }}(j)\right)($ Figure $2 a)$.

On the hydrocarbon side, the measured quantities are the flow temperatures at every second row of tubes $\left(T_{2}(1) \ldots T_{2}(9)\right)$, the pressure drop $\Delta p$ between the top and the bottom of the bundle and the local void fraction. The entrance conditions of the fluid are known from the recorded temperature $T_{2}(0)$, pressure $p(0)$ and mass flow rate $M_{2 L}$ (Figure $2 a$ ). The nominal ranges of experimental conditions covered in this investigation are listed in Table 1. The calculation of uncertainties was evaluated for all the operating conditions. It was founded that the temperature uncertainties were less than $0.5 \mathrm{~K}$. The pressure level and mass flux uncertainties were less than $5 \%$ and the void fraction were less than $1 \%$. Using the method proposed by Moffat (1998), the maximum uncertainties in vapour quality, heat transfer coefficient and heat flux were less than $25 \%$ for all the operating conditions.

\subsection{Optical fibre probe}

The void fraction measurement system is composed by an optical probe, a transmitter and an infra-red light detector (Figure 3b). The optical system is made up of a silica optical fibre with only one connector on the whole length. The optical fibre is held in a $2 \mathrm{~mm}$ diameter rigid sheath, and ended by a sapphire point of $0.4 \mu \mathrm{m}$ in diameter (Figure 3a). Its tip is cone-shaped to allow the precise detection of bubbles with a minimum diameter of $80 \mu \mathrm{m}$. The choice of the sapphire point is justified by its greater robustness, which is necessary in the industrial environment. The local void fraction $\varepsilon$ is measured at three positions 
on an inclined line between the tubes, along which the optical probe can move within an accuracy of 0.05 $\mathrm{mm}$. The three measurements are equidistant to $2.1 \mathrm{~mm}$ around the central position 2 (Figure $2 b$ ). The void fraction recording is based on the difference of refraction index between the liquid and the vapour. The signal coming from the emission diode is sent continuously by the optical fibre. When the tip of the probe is in the liquid, the signal is refracted and the detector gives a low voltage level. On the contrary, when the probe is in the vapour, the signal is reflected and returns to the reception diode which gives a high voltage level. An electronic circuit converts the direct signal coming from the detector into a TTL square signal. Analogous and digital signals are visualised simultaneously on an oscilloscope and this makes the quality control of the measurements possible. The gain of the detector is fixed to have a difference of $6 \mathrm{~V}$ between the high and the low levels of the analogous signal; the detection threshold of a bubble is fixed at $0.77 \mathrm{~V}$. Under these conditions, the observed noise is always lower than $0.4 \mathrm{~V}$. The duration of all the high level signals is summed to determine the total time $t_{G}$ during which the probe detects the vapour. The void fraction $\varepsilon$ is defined as the ratio of $t_{G}$ time over the total recording time $T_{R}$ :

$$
\varepsilon=\frac{t_{G}}{T_{R}}
$$

The measuring system used for the $n$-pentane (Roser (1999)) and propane allowed a recording time of 6.4 s. This value corresponds to the maximum capacity of the buffer memory of the acquisition card working at a sampling rate of $5 \mathrm{kHz}$. For the iso-butane data, the sampling rate was $2 \mathrm{kHz}$ without any notable loss of information with a total recording time of $160 \mathrm{~s}$. A PC-based data acquisition system with a National Instrument NI-PCI-6013 high speed A/D data acquisition board and LabView software was used to record the digital signal of the void fraction from the optical probe.

\section{Data analysis}

If $P(\varepsilon)$ is the probability that the void fraction, $\varepsilon$, is less than some specific value, then $d P(\varepsilon) / d \varepsilon=p(\varepsilon)$ represents the probability per unit void fraction that the void fraction lies between the values of $\varepsilon$ and $\varepsilon+d \varepsilon$. During the total time recording $T_{R}$, the void fraction and the time scale can be divided into equal increments of $\Delta \varepsilon$ and $\Delta t$ respectively. The void fraction appears $n_{i}$ times between $\varepsilon_{i}$ and $\varepsilon_{i}+d \varepsilon_{i}$. If $N$ is the number of $\Delta t$ windows for the total time recording $T_{R}$, we have:

$$
\frac{n_{i} / N}{\Delta \varepsilon_{i}}=\frac{1}{\Delta \varepsilon_{i}} \sum_{k=1}^{n_{i}} \frac{t_{G, k}}{T_{R}}
$$


In the case of bubbly flow, a large ratio $n_{i} / N$ occurs at low void fraction while a smaller ratio exists for higher values of the void fraction. The ratio $\Sigma(\Delta t / T)$ represents the probability that the void fraction lies within the given interval, bounds around $\varepsilon_{i}$. Then the $P D F$ can be given by:

$$
\lim _{\Delta \varepsilon_{i} \rightarrow 0} \frac{1}{T_{R} \Delta \varepsilon_{i}} \sum_{k=1}^{n_{i}} t_{G, k}
$$

If $\Delta t$ is small enough, the $P D F$ can be evaluated by using the left or right hand side of equation (2). In the present investigation, the $P D F$ has been carried out on the instantaneous digital signal of the local void fraction. The digital signal is cut in $8000 \Delta t$ windows (Figure 4), and the partial void fraction in each window is calculated by (1)

$$
\varepsilon_{j}(t)=\frac{t_{G, j}}{\Delta t}
$$

The amount $n_{i}$ of partial void fraction $\varepsilon_{j}(t)$ for each interval $\Delta \varepsilon$ is added up $n_{i}=n_{i}+1$ when $\varepsilon_{i}<\varepsilon_{j}<\varepsilon_{i}+\Delta \varepsilon_{i}$. Finally, the $P D F_{i}$ relative to the void fraction interval $\Delta \varepsilon_{i}$ is defined by:

$$
P D F_{\varepsilon i}=\frac{n_{i} / N}{\Delta \varepsilon} \quad i=1 \ldots 20
$$

The void fraction scale is divided into 20 intervals $(\Delta \varepsilon=0.05)$ and the total recording time into $8000 \Delta t$ windows.

\subsection{Choice of the $\Delta t$ duration sample determination}

The $P D F$ shapes are closely related to the windows duration $\Delta t$. To investigate this, an analysis of its influence has been realised. Figure $5 a, b, c$ show the PDF of the recorded signal for three different mean void fractions by using several $\Delta t$ values. It is clearly shown that a decrease of the time scale $\Delta t$ from $0.5 \mathrm{~s}$ to $0.005 \mathrm{~s}$ induces significant modifications of the normalised PDF function. For the smallest values of time cut, all the curves present an increase for low void fraction values and also for high values. For the highest time cuts $(0.5 \mathrm{~s})$ the curves normally present an accentuation of the peak around the mean void fraction.

In fact, the $\Delta t$ window implemented must be large to visualise high void fraction time variations and also sufficiently small so as to have variations of the instantaneous void fractions. The choice of the $\Delta t$ parameter is consequently difficult to evaluate. As a result, a quantitative method must be implemented to determine the value of this window in order to realise a quantitative analysis of the flow patterns. 
To obtain a quantitative value of $\Delta t$, an analysis of the instantaneous cross-correlation void fraction functions $R_{x, x}(\tau)$ was performed.

$$
R_{x x}(\tau)=\varepsilon(t) \otimes \varepsilon(t+\tau)
$$

This approach allows us to pin-point the time at which the signals are no longer correlated and hence to achieve a better evaluation of the characteristic times. Figure 6 presents a representative sample of the results obtained for the three hydrocarbons at various operating conditions. It can be noticed that the signals differ from one fluid to another, and also for different operating conditions. The iso-butane and the $n$-pentane signals are no longer correlated for times above $0.01 \mathrm{~s}$ and for propane approximately $0.02 \mathrm{~s}$. To simplify the systematic analysis we chose the same time interval for the three hydrocarbons corresponding to the highest value deduced from the cross correlation function, $0.02 \mathrm{~s}$. This choice is not unique.

\subsection{Characterisation of the flow regimes by statistical analysis}

To complete this approach a statistical analysis has also been realised. The latter is based on the determination of the higher moments (second, third and fourth) to allow an interpretation of the void fraction variation according to different flow regimes.

The general form of the moments $(r>2)$ of a $P D F$ is given as:

$$
M_{r}=\frac{1}{N} \sum_{i=1}^{N}\left[Z_{i}(t, x)-\bar{Z}\right]^{r}
$$

The first moment $M_{l}$, equal to zero, provides the arithmetic mean value of the variable $Z$. The second moment $M_{2}$ is the root-mean square deviation from the mean value. The third moment $M_{3}$ allows the evaluation of the curve's asymmetry around the mean value. And finally, the fourth moment $M_{4}$ represents the distribution concentration around a peak.

The skewness coefficient $C_{M 3}=M_{3} / M_{2}^{3 / 2}$ and kurtosis coefficient $C_{M 4}=M_{4} / M_{2}{ }^{2}$ are used to characterise the probability density histograms as illustrated in Figure 7 and Figure 8. Figure $7 a$ proposes a schematic histogram with a positive coefficient of skewness which means that many events $N$ occur at small values of the variable. Figure $7 b$ gives a Gaussian distribution of events and, in Figure $7 c$, a negative coefficient of skewness indicates a great number of events at high values of the variable. 
In the case of a Gaussian distribution (or normal law), odd moments are zero and even moments are calculated by:

$$
M_{2 n}=\frac{(2 n) !}{n !}\left(\frac{M_{2}}{2}\right)^{n}
$$

The schematic histograms for different coefficients of kurtosis $C_{M 4}$ are presented in Figure 8 . In the case of a Gaussian distribution of a variable, $C_{M 4}$ is equal to 3 (Figure $8 b$ ). For $C_{M 4}>3$ a great number of events occur in a region around the peak (Figure $8 a$ ). For $C_{M 4}<3$, the events are spread as a large range around the peak (Figure 8c).

A statistical study will be performed so as to characterise the flow regimes. The analysis of the third and fourth order moments will help, and can be used to obtain information on the size of the bubbles through the $C_{M 3}$ coefficient, and also on their distributions in the flow with the $C_{M 4}$ coefficient.

\section{Results and discussion}

\subsection{Local mean void fraction analysis}

Global thermal conditions of reboilers are partially governed by hydraulic conditions at the tube scale. In order to characterize the two-phase flow in the bundle, we compared the experimental data of the void fraction for each hydrocarbon with the Homogeneous Model (HM). The mean void fraction was calculated by an average of positions 1,2 and 3 between the tubes (Figure 2b). These three positions have been selected because of their location in the main flow between the tubes at the minimum cross section. Figure 9 compares the homogeneous model with the experimental results for each hydrocarbon, at the same mass velocity based on the minimum cross-section $\left(m_{2 L}=15 \mathrm{~kg} \cdot \mathrm{m}^{-2} \cdot \mathrm{s}^{-1}\right)$. The experimental values are significantly lower than the prediction of the homogeneous flow model where the slip factor is not considered. This over-prediction is found for the three hydrocarbons and all the operating conditions investigated. The comparison of the hydrocarbon measurements reveals that the void fraction for $n$ pentane is higher than for the two other fluids. This is due to a lower operating pressure inducing a larger density ratio $\left(\rho_{L} / \rho_{G}\right)$ for $n$-pentane. This is in accordance with the Martinelli and Nelson (1948) investigation. It shows that for a given vapour quality a decrease in operating pressure for steam-water leads to an increase in void fraction. Dowlati et al. (1993) have also observed this trend for R-113 boiling flow in a staggered tube bundle. On Figure 9, propane and iso-butane give approximately the same void fraction results since their physical properties are similar at the same operating pressure. 
To take into account the void fraction variations in terms of the physical properties, the drift flux model has been applied to our results for the three hydrocarbon fluids. Initially developed by Zuber and Findlay (1965), this model suggests that the average gas velocity $U_{G}$ is linearly related to the superficial velocity $j$ as,

$$
\overline{U_{G}}=C_{0} j+U_{G j} \text { with }\left\{\begin{array}{l}
\overline{U_{G}}=\frac{m_{2 L} \cdot x}{\rho_{G} \cdot \varepsilon} \\
j=\frac{m_{2 L} \cdot x}{\rho_{G}}+\frac{m_{2 L} \cdot(1-x)}{\rho_{L}}
\end{array}\right.
$$

where $C_{0}$ represents the void fraction distribution parameter and $U_{G j}$ is the drift velocity. In Figure 10 the results for n-pentane, propane and iso-butane are plotted.

Using a linear regression, the following fitted curve was obtained with an average deviation of $20 \%$ for the three hydrocarbons:

$$
\overline{U_{G}}=1.047 j+0.23
$$

The fact that $C_{0}$ is different from unity and $U_{G j}$ is different from zero, clearly indicates that the homogeneous model fails. The obtained value of $C_{0}(1.047)$ is similar to the values obtained by Dowlati et al. $(1992,1993)$ for air-water $(1.104)$ and R-113 (1.076). On the contrary, the value of $U_{G j}(0.23)$ is lower than those obtained by Dowlati et al. $(1992,1993)$ for air-water flow $(0.33)$ and R113- boiling flow $(0.85)$.

Equation 10 correlates all our experimental data bank. The Zuber and Findlay's approach (1975) leads to a single relation for the whole of the investigated operating conditions (fluid, pressure, mass flow rate and heat flux). This representation doesn't show the differences in the fluid flow behaviour. To overcome this deficiency another approach must be implemented.

\subsection{PDF description}

To determine the flow regimes for convective boiling in a staggered bundle, the PDF method associated with moments of higher orders was developed and applied on hydrocarbon void fraction recordings. This method was used for the first time by Zuber and Jones (1975) to obtain a quantitative representation of the flow patterns in a narrow rectangular channel. It was also used successfully thereafter by Hahne et al. 
(1990) to analyse the flows regimes of refrigerants in pool boiling conditions outside a bundle of finned tubes, and by Noghrekhar et al. (1999) for adiabatic air-water flows on smooth tubes bundle in both a square and a staggered configuration.

Figure 11 represents three typical PDF of the local void fraction obtained with iso-butane and their associated void fraction signals. The PDF data showing a single peak at low void fractions, is obtained for signals of events of short time duration; they represent bubbly flow (Figure 11a). Conversely, the PDF data showing one peak at high void fractions is obtained for signals of events with high time duration; they represent annular-dispersed flow (Figure 11c). Between these two regimes, an intermittent regime can be identified as a combination of the two others. The void fraction time series is composed of two types of signals: high time duration of the void fraction (characteristic of annular-dispersed flow) and small time duration of void fraction (characteristic of the bubbly flow). On the corresponding PDF, two peaks are found: one at low void fraction for small bubbles and one at high void fraction for large bubbles (Figure 11b). Nevertheless, qualitative comparison between PDF curves is not satisfactory. A quantitative study must be undertaken using statistical tools.

\subsection{Sensitivity of PDF to operating conditions}

The analysis of the PDF variations according to the hydrocarbon mass velocity rate and the heat flux were performed in order to understand the flow regime evolution as well as the mechanisms leading to the transitions. In the case of a two-phase-flow in a confined and tortuous space, two physical mechanisms support the creation of the flow regimes: the fragmentation and the coalescence of the bubbles. Fragmentation breaks up and divides large vapour slugs into smaller ones, and coalescence results from the gathering of small bubbles into a large vapour slug. Figure 12 shows for each flow regime the evolution of a PDF with increasing mass flow rate for a given heat flux. For bubbly flow (Figure 12a), the peak which appears at $\varepsilon=0.2$ for $m_{2 L}=31 \mathrm{~kg} \cdot \mathrm{m}^{-2} \cdot \mathrm{s}^{-1}$ is attenuated and moves to a higher values for higher mass flow rates. For the three regimes, an increase in mass flow rate causes a reduction of the number of events at low void fractions and an increase at large void fraction (Figure 12a-b-c). The tube bundles compactness in a staggered configuration obliges the bubbles to coalesce to form large vapour slugs of significant size. This interpretation differs from Hahne's one (1990) probably because of the use of finned tubes in his study.

In addition, we noticed a strong influence of the heat flux on $P D F$ curves. Comparison of the different curves on Figure 12a-b-c shows that for the same massflow rate $\left(m_{2 L}=39 \mathrm{~kg} \cdot \mathrm{m}^{-2} \cdot \mathrm{s}^{-1}\right)$ an increase of the 
heat flux causes more important changes in the flow regimes than the increase of the hydrocarbon flow. As the heat flux increases, bubbles forming on the tubes are more numerous. When they separate from the wall, they tend to join and coalesce with the vapour already present in the main flow. The quantity of vapour produced is more important at higher heat flux, the coalescence will be enhanced and the flow transition will occur earlier than for adiabatic two-phase flow.

\subsection{Characterisation of flow regimes}

The previous analysis shows the difficulty to separate and to characterise the different flow regimes with only the use of the PDF curves. This is why a statistical analysis based on the local void fraction measurements was also performed. The approach consists in analysing the void fraction signal with moments of order 3 and 4 . The variations of these moments allow the PDF shape and consequently the flow regimes to be defined.

In Figure 13 the standard deviation from the mean value of void fraction is presented for all operating conditions and for the three hydrocarbons. As we can see, the whole of the void fraction range is covered from 0 to 1 . Almost all the $M_{2}$ values are grouped together in the same curve. The fitted curve presents a parabolic shape. Propane and $n$-pentane appear respectively at low and high void fractions. For iso-butane it was possible to carry out measurements on a broader range of void fractions. The $M_{2}$ coefficient has a maximum value of 0.35 for the void fraction value of 0.5 . A low value of $M_{2}$ represents a flow regime where the vapour structures (bubbles or slugs) have the same size. Conversely, large values of $M_{2}$ reveal the existence of both small and large vapour structures. The comparison between the hydrocarbons shows some differences. The propane experiments were located at low void fractions, while the $n$-pentane experiments were located at high void fractions. The iso-butane experiments covered all the void fraction range.

In Figure 14 the kurtosis coefficient $C_{M 4}$ is plotted for all of the data; a $C_{M 4}$ value larger than 3 means that all the events are concentrated around the mean value (Figure $8 a$ ). For a low void fraction $(\varepsilon<0.35)$, almost all the tests of propane and some of the iso-butane tests (those at a low heat flux and a low mass flow rate) present a $C_{M 4}$ value larger than 3. According to the previous analysis (Figure 13 and Figure 14) we assume that these regimes are composed of small bubbles of similar size. For high void fraction measurements $(\varepsilon>0.56), C_{M 4}$ values of $n$-pentane and iso-butane are larger than 3 . The flow is composed 
of vapour slugs of the same size. It should be noted that it is difficult to precisely evaluate the width of the transition zone because the minimum values of $C_{M 4}$ are close to 3 . However, for $0.35<\varepsilon<0.56$ (which comprises most of the iso-butane results) the coefficient is around 3 and confirms that these flows include a large variety of events distributed according to a normal law.

In Figure 15 the coefficient of skewness $C_{M 3}$ is presented for all the fluids investigated. For void fraction lower than 0.35 , the coefficient is clearly positive. According to Figure $7 a$ the PDF data presents a peak for low void fractions; this means that there is a large number of small bubbles present in the flow. For a higher void fraction $(0.35<\varepsilon<0.56)$, the coefficient is around zero $\left(-0.5<C_{M 3}<0.5\right)$. The flow is composed of bubbles of different sizes distributed according to a Gaussian curve (Figure 7b). This flow regime is assumed to be representative of an intermittent regime due to the alternative presence of small and large bubbles. For void fractions higher than 0.56 , the coefficient is negative and drops quickly. According to Figure $7 c$, this indicates a great number of events at high void fractions, representative of an annulardispersed flow.

In summary, the flow regimes can be separated in the following way:

- $\quad$ Bubbly flow regime for a void fraction lower than 0.35 ,

- $\quad$ Annular -dispersed flow regime for a void fraction higher than 0.56,

- $\quad$ Intermittent flow regime for a void fraction varying in a range between 0.35 and 0.56 .

\subsection{Flow regime descriptions and flow map}

The statistical analysis highlighted three flow patterns. To obtain more information on two-phase flow regimes, an analysis of the mean bubble diameter $\overline{d_{B}}$ was performed. This diameter is calculated as:

$$
\overline{d_{B}}=\overline{t_{B}} \cdot \overline{U_{G}}
$$

The average time $\overline{t_{B}}$ of flowing bubbles has been evaluated as,

$$
\overline{t_{B}}=\frac{\sum_{i=1}^{N} n_{i} t_{i}}{N}
$$

Where $n_{i}$ is the number of bubbles which have a duration time $t_{i}$, and $N$ is the total number of time data recorded. $\overline{U_{G}}$ is the mean real vapour velocity : 


$$
\overline{U_{G}}=\frac{m_{2 L} \cdot x}{\rho_{G} \cdot \bar{\varepsilon}}
$$

Figure 16 shows the evolution of the average bubble size for the three hydrocarbons. For void fractions lower than 0.35 , the mean bubble diameter is lower than the minimum space between the tubes (Figure $2 b$ ). When the bubbles reach a critical size, which corresponds to the minimum space between the tubes, the flow becomes chaotic. Alternative passages of small and large vapour structures occurs, this corresponds to the two peaks of the intermittent regime (Figure 11b). For a higher mean void fraction the bubbles are bigger and close to each other, the interfaces between the vapour slugs breaks and a continuous vapour phase, in which liquid droplets can be involved, is generated. This annular-dispersed flow, which appears for void fractions higher than 0.56 , presents an average size of bubble ranging between 2.5 and 7 times the tubes clearance.

These flow regime results could be interpreted using the fluid physical properties. The propane whose vapour density is most significant for the given operating conditions, mainly produces a bubbly flow regime. Conversely, n-pentane which has the lower vapour density for the operating conditions used is exclusively located in the annular-dispersed flow regime. Iso-butane which has vapour densities ranging in-between propane and $n$-pentane, covers all of the three flow regimes.

As in the case of convective boiling inside a tube, the flow structure outside of a tube bundle is controlled by the heat flux, the hydrocarbon mass flow rate and the physical properties. However, the effects of the obstacles and the tortuosity will induce flow transitions at lower void fractions. In a tube bundle, the extent of the transition zone is partly due to the agitation and the dynamic effects of the two-phase flow which tends to divide larger vapour slugs in smaller ones, and then increases the transition zone between the bubbly and the annular-dispersed flow.

Figure 17 is a schematic representation of the two flow regimes.

Bubbly flow is characterized by a vapour phase distributed as discrete bubbles in the continuous liquid phase (Figure 17a). These bubbles initially detaching from nucleation sites on tube walls. Kondo and Nakajima (1980) and Ulbrich and Mewes (1994) noted that bubbles have a uniform size with a characteristic diameter lower than the space between the tubes.

Annular-dispersed flow is characterised by a continuous gas phase in which the liquid droplets are carried (Figure 17b). The larger fraction of the flow area in a tube bundle is occupied by the vapour phase in the form of channels between the tubes. The liquid phase mainly occupies the recirculation zone between the tubes, and has an irregular movement with surface waves on the tube walls. 
Intermittent flow is characterized by a superposition of bubbly and annular-dispersed flows.

The few established flow regimes found compared to those obtained for two-phase flows in vertical tubes, is mainly due to the presence of tubes whose effect is to confine a flow in a complex geometry. The experimental data were first compared to the flow map proposed by Noghrehkar et al. (1999). These authors evidenced the transition zone for a staggered tube bundle $(\mathrm{p} / \mathrm{d}=1.47)$ in adiabatic conditions (airwater mixture) as shown in dashed lines on Figure 18. As we can see on this figure, the flow transitions proposed by these authors differ highly from our flow boiling conditions. The main differences are:

- The transitions for flow boiling conditions are moved towards lower superficial vapour velocity.

- In flow boiling the transitions depend only on vapour velocities, liquid velocities do not play a role.

- The width of the transition zone between the bubble and annular-dispersed flows is significantly smaller for boiling flow (superficial gas velocity between 0.15 and 0.35 ) compared to adiabatic two-phase flow (between 0.45 and 3.9).

These differences might be explained by the fact that in adiabatic conditions the two-phase flow is organized from the bottom of the bundle and only influenced by the geometrical configuration of the tube bundle. In flow boiling conditions the vapour is generated on the tube wall, and all along the bundle. This effect combined with the complex geometry of the obstacles (tubes bundle) involves large disturbances of the two-phase flow. This leads to a shift in the transition zone towards smaller void fractions.

As a result, a new flow regime map is proposed for flow boiling in tube bundles. The limits between the flow regimes are determined according to the constant superficial vapour velocities $j_{G}$ (Figure 18). The limits between bubbly and intermittent flow are $j_{G}=0.15 \pm 0.03 \mathrm{~m} \cdot \mathrm{s}^{-1}$, and between intermittent and annular-dispersed flow are $j_{G}=0.35 \pm 0.03 \mathrm{~m} . \mathrm{s}^{-1}$. The error uncertainties in both the vapour quality and the mass flowrate are included in the data range and limits.

\section{Conclusions}

Two-phase flow patterns in a staggered tube bundle were investigated for three hydrocarbons at boiling conditions. The experimental device and the local instrumentation implemented appears well adapted to the analysis of boiling outside horizontal tube bundles. A method of the local void fraction analysis in such a complex geometry was successfully developed. Three hydrocarbons were explored under several operating conditions (pressure, heat flux and massflow rate). In this study a quantitative method for the 
determination of flow structures for boiling conditions outside horizontal tube bundle has been proposed. The correlation of Zuber and Findlay (1965) was applied to the void fraction data with a good agreement and a unique relationship between $j_{G}$ and $U_{G}$ was obtained for the three fluids. This correlation is rather directed towards practical applications, and does not provide a comprehensive analysis of two-phase flow phenomena.

The statistical analysis of the void fraction signals allows a clear identification of two regimes bubbly and annular-dispersed flow, separated by an intermediate regime. The latter corresponds to the superposition of the two main modes. The statistical analysis showed that, for the investigated conditions, propane flows are mainly bubbly and $n$-pentane flows are mainly annular-dispersed. For $i s o$-butane both bubbly and annular-dispersed regimes are evidenced. The transitions between these regimes were identified and correspond to void fraction thresholds. Bubbly flow is found for void fraction values lower than 0.35 while annular-dispersed flow is found for values higher than 0.56 .

A flow map based on the superficial vapour and liquid velocities $\left(\mathrm{j}_{\mathrm{G}}, \mathrm{j}_{\mathrm{L}}\right)$ has been proposed for tube bundles with a pitch-to-diameter ratio equal to 1.33 . It has been shown that the transition regimes were found for a superficial vapour velocity of $0.15 \pm 0.03 \mathrm{~m} \cdot \mathrm{s}^{-1}$ and $0.35 \pm 0.03 \mathrm{~m} . \mathrm{s}^{-1}$. The study showed the major roles of the fluid physical properties such as the liquid and vapour densities on the regimes. The proposed flow map covers a large range of operating conditions for three hydrocarbons at different operating conditions. Moreover, it will be interesting to analyse the validity of the proposed map with other fluids such as non-hydrocarbon fluids.

Future works must be directed towards the influence of the geometrical parameters. It seems that the space between the tubes is a dominating parameter, not on the nature of the flow regimes but on the transition between these regimes.

Based on the present flow regime map, the heat transfer and pressure drop laws must be established. An investigation will be carried out to highlight the existing relationship between the thermohydraulic laws and the flow regime map. 


\section{References}

Ali, I.M., Kawaji, M., Sadatomi, M., 1993. Adiabatic two-phase flow in narrow channels between two flat plates. Can. J. Chem. Engng 71, 657-666.

Baker, O., 1954, Simultaneous flow of oil and gas. Oil and Gas J. 53, 185-195.

Bell K.J., Taborek, J., Fenoglio, F., 1970. Interpretation of horizontal intube condensation heat transfer correlations with two-phase flow regime map. Chem. Engng. Prog. Symp. Ser., vol. 66, n¹02, 150165.

Bennet, A.W., Hewitt, G.F., Kearsey, H.A, Keeys, R.F.K., Lacey, P.M.C., 1965. Flow visualisation studies of boiling at high pressure. Inst. Mech. Eng. Proc. 180, part 3C, 260-270.

Consolini, L., Robinson, D., Thome, J.R., 2006. Void fraction and two-phase pressure drops for evaporating flow over horizontal tube bundles. Heat Transfer Engineering, vol. 27(2) or vol. 27(3).

Cornwell, K., Duffin, N.W., Schüller, R.B., 1980. An experimental study of the effects of fluid flow on boiling within a kettle reboiler tube bundle. ASME, 80-HT-45.

Dowlati, R., Kawaji, M., Chan, A., 1990. Pitch-to-diameter effect on two-phase flow across an in-line tube bundle. AIChE Journal 36, n5, 765-777.

Dowlati, R., Kawaji, M., Chisholm, D., Chan, A., 1992a. Void fraction prediction in two phase flow across a tube bundle. AIChE J. 38, n4, 619-622.

Dowlati, R., Kawaji, M., Chan, A., 1992b. Hydrodynamics of two-phase flow across horizontal in-line and staggered rod bundles. ASME J. Fluids Engineering 114, 450-456.

Dowlati, R., Kawaji, M., Chan, A., 1993. Measurement of void fraction and pressure drop in flow boiling of R-113 across horizontal tube bundles. ASME, 93-HT-17.

Dowlati, R., Kawaji, M., Chan, A., 1996. Two-phase crossflow and boiling heat transfer in horizontal tube bundles. ASME J. Heat Transfer 118, 124-131.

Feenstra, P.A., Weaver, D.S., Judd, R.L., 2000. An improved void fraction model for two-phase crossflow in horizontal tube bundles. Int. J. of Multiphase flow 26, 1851-1873.

Gebbie, J.G., Jensen, M.K., 1996. Void fraction distributions in a Kettle reboiler. Experimental Thermal and Fluid Sciences, vol. 14, 297-311.

Govier, G.W., Aziz, K., 1972. Flow of complex mixtures in pipes. Van Nostrand-Reinhold Co., New York, 554-613.

Grant, I.D.R., Murray, I., 1972. Pressure drop on the shell-side of a segmentally baffled shell-and-tube heat exchanger with vertical two-phase flow. National Engineering Laboratory, NEL Report n500. 
Hahne, E., Spindler, K., Chen, Q., Windisch, R., 1990. Local void fraction measurements in finned tube bundles. Heat Transfer 1990, Proceeding of the $9^{\text {th }}$ International Heat Transfer Conference 6, 41-46.

Hewitt, G.F., Hall-Taylor, N.S., 1970. Annular two-phase flow. Pergamon Press.

Hewitt, G.F., Roberts, D.N., 1969. Studies of two-phase flow patterns by simultaneous X-ray and flash photography. AERE-M2159.

Jensen, M.K., Hsu, J.T., Lin, C.S., 1993. Boiling heat transfer mechanisms in a horizontal tube bundle. Experimental Heat Transfer 6, 259-271.

King, M.P., Jensen, M.K., 1995. Local heat transfer and flow pattern distributions in kettle reboiler. Twophase flow modelling and experimentation 1995, Celata C.P. and Shah R.K. (eds.), Edizioni ETS, vol.2, 1289-1296.

Kondo, N., Nakajima, K.I., 1980. Experimental investigation of air water two-phase upflow across horizontal tube bundles-Part I flow pattern and void fraction. Bulletin of JSME 23, n 177, 385-393.

Leong, L.S., Cornwell, K., 1979. Heat transfer coefficients in a reboiler tube bundle. The Chem Engineer $343,219-221$.

Lian, H.Y., Noghrehkar, G., Chan, A.M.C., Kawaji, M., 1997. Effect of void fraction on vibrational behavior of tubes in tube bundle under two-phase cross flow. J. of vibration and acoustic 119, 457463.

Lockhart, R.W., Martinelli, R.C., 1949. Proposed correlation of data for iso-thermal two-phase, twocomponent flow in pipes. Chem. Eng. Prog. 45 (1), 39-48.

Martinelli, R.C., Nelson, D.B., 1948. Prediction of pressue drop during forced-circulation boiling of water. Trans. ASME 65, 219-221.

Moffat, R.J., 1998. Describing the uncertainties in experimental results. Experimental Thermal and Fluid Science, vol. 1, 3-17.

Noghrehkar, G.R., Kawaji, M., Chan, A.M.C, 1999. Investigation of two phase flow regimes in tube bundles under cross-flow conditions. Int. J. Multiphase Flow 25, 857-874.

Oshinowo, T., Charles, M.E., 1974. Vertical two-phase flow. Part I. Flow pattern correlations. The Canada J. Chem. Engng. 52, 25-35.

Palen, J.W., Yang, C.C., 1983. Circulation boiling model for analysis of kettle and internal reboiler performance. In: Kitto J.B., Robertson J.M. (Eds), Heat Exchangers for Two-Phase Applications, HTD 27, ASME, New-York, 55-61.

Polley, G.T., Ralston, T., Grant, I.D.R., 1980. forced crossflow boiling in an ideal in-line tube bundle. ASME paper $\mathrm{N}^{\circ} 80-\mathrm{HT}-46$. 
Rahman, F.H., Gebbie, J.G., Jensen, M.K., 1996, An interfacial friction factor correlation for shell-side vertical two-phase cross-flow past horizontal inline and staggered tube bundles. Int. J. of Multiphase flow, vol. 22, 753-766.

Roser, R., 1999. Modélisation thermique de bouilleurs à tubes horizontaux. Etude numérique et validation expérimentale. Thèse de Doctorat, Polytech' Marseille laboratoire IUSTI, Université de Provence Aix-Marseille I, France.

Schrage, D.S., Hsu, J.T., Jensen, M.K., 1987. Void fractions and two-phase and two-phase friction multipliers in a horizontal tube bundle. AIChE Symposium Series, vol. 83, n²57, 1-8.

Schrage, D.S., Hsu, J.T., Jensen, M.K., 1988. Two-phase pressure drop in vertical crossflow across a horizontal tube bundle. AIChE Journal 34, $\mathrm{n}^{\circ} 1,107-115$.

Taitel, Y., Dukler, A.E., 1976. Flow regime transitions for vertical upward gas-liquid flow : a preliminary approach through physical modelling. AICHE $70^{\text {th }}$ Annual Meeting, New York, Session on fundamental Research in Fluid Mechanics.

Thome, J.R., El Hajal, J., 2003. Two phase flow pattern map for evaporation in horizontal tubes: Latest version. Heat Transfer Engineering, vol. 24,nº 6 , 10 .

Ulbrich, R., Mewes, D., 1994. Vertical, upward gas-liquid two-phase flow across a tube bundle. Int. J. Multiphase flow 20, $\mathrm{n}^{\circ} 2,249-272$.

Webb, R.L., Chien, L.H., 1994. Correlation of convective vaporization on banks of plain tubes using refrigerants. Heat Transfer Engineering 15, n 3, 57-69.

Whalley, P.B., Butterworth D., 1983. A simple method for calculating the recirculating flow in vertical thermosyphon and kettle reboiler. In Heat Exchangers for Two-Phase applications. HTD 27, ASME, New-York, 47-53.

Zuber, N., Findley, J.A., 1965. Average volumetric concentration in two-phase flow systems. J. Heat transfer, 453-468.

Zuber, N., Jones, O.C. Jr., 1975. The interrelation between void fraction fluctuations and flow patterns in two-phase flow. Int. J. Multiphase Flow 2, 273-306.

Zürcher, O., Favrat, D., Thome, J.R., 2002, Development of a diabatic two-phase flow pattern map for horizontal flow boiling. Int. J. Heat Mass Transfer, vol. 45, 291-303. 
Figure 1 Sketch of the experimental apparatus. (a) Boiling two-phase flow installation, (b) tube bundle test section.

Figure 2 Sketch of the tube bundle test section with measured quantities (a) and location of void fraction measurements with an optical probe system (b).

Figure 3 Void fraction measurements system (a) sectional of the optical probe tip and (b) diagram of the fibre optical system.

Figure 4 Typical instantaneous void fraction variation signal versus time, and time windows method used for statistical analysis.

Figure 5 Influence of the time duration sample variations on PDF data for regimes, (a) Bubbly flow, (b) intermittent flow, and (c) annular-dispersed flow.

Figure 6 Cross correlation functions for various hydrocarbons $-\mathrm{n}$-pentane $\left(\mathrm{p}=0.3 \mathrm{bar}, \mathrm{q}=44 \mathrm{~kW} . \mathrm{m}^{-2}\right.$, $\left.\mathrm{m}_{2 \mathrm{~L}}=44 \mathrm{~kg} \cdot \mathrm{m}^{-2} \cdot \mathrm{s}^{-1}\right)$; propane $\left(\mathrm{p}=6\right.$ bar, $\left.\mathrm{q}=6 \mathrm{~kW} \cdot \mathrm{m}^{-2}, \mathrm{~m}_{2 \mathrm{~L}}=15 \mathrm{~kg} \cdot \mathrm{m}^{-2} \cdot \mathrm{s}^{-1}\right)$; iso-butane $\left(\mathrm{p}=4 \mathrm{bar}, \mathrm{q}=52 \mathrm{~kW} \cdot \mathrm{m}^{-2}\right.$, $\left.\mathrm{m}_{2 \mathrm{~L}}=46 \mathrm{~kg} \cdot \mathrm{m}^{-2} \cdot \mathrm{s}^{-1}\right)$.

Figure 7 Schematic histograms for the three different coefficients of skewness $\mathrm{C}_{\mathrm{M} 3}$.

Figure 8 Schematic histograms representation for the three different coefficients of kurtosis $\mathrm{C}_{\mathrm{M} 4}$ in the case of a Gaussian function of void fraction.

Figure 9 Local mean time void fraction profile versus vapour quality. A comparison of the experimental data with the homogenous model for boiling hydrocarbons.

Figure 10 Vapour velocity versus total superficial velocity for the three hydrocarbons propane, iso-butane and n-pentane. Analysis of the experimental data with the drift flux model. The points are deduced for each experiment. $U_{G}$ is deduced from the local measurement (liquid massflow rate $m_{2 L}$, vapour quality $x$, void fraction $\varepsilon$, vapour density $\rho_{G}$ ). The curve is obtained by fitting the experimental points. The Zuber and Findlay's coefficients are then deduced $\left(C_{0}=1.0466, U_{G j}=0.23\right)$. 
Figure 11 Typical probability density function of the local void fraction signal for the three regimes (a) bubbly flow, (b) intermittent flow, (c) annular-dispersed flow for iso-butane boiling in a staggered tube bundle. The operating conditions are displayed on each graph. A sample of the void fraction time signal is also shown.

Figure 12 Probability Density Function variation of local void fraction signal for (a) bubbly flow, (b) intermittent flow, (c) annular-dispersed flow for iso-butane boiling on a staggered tube bundle.

Figure 13 Variation of $M_{2}$ coefficient of local void fraction for three hydrocarbons on a staggered tube bundle. The points are deduced from the experimental values of void fraction signal. Far from the intermittent regime, i.e. for bubbly and annular-dispersed flow, the RMS decreases.

Figure 14 The kurtosis coefficient of local void fraction for three hydrocarbons on a staggered tube bundle. This coefficient measures the concentration of experimental values around a peak. We confirm that for bubbly flow (small void fraction), and annular-dispersed flow (high void fraction) the PDF is represented by a single peak as shown on Figure 8a-c. In the intermittent regime, the PDF presents two peaks representative of a Gaussian distribution of small and large vapour bubbles (Figure 8b)

Figure 15 The skewness coefficient of local void fraction for three hydrocarbons on a staggered tube bundle. This coefficient measures the asymmetry of the PDF. We confirm that for bubbly flow (small void fraction), and annular-dispersed flow (high void fraction) the PDF is non symmetric as shown on Figure 7a-c. In the case of intermittent regime, the PDF is symmetric around the mean void fraction (Figure 7b)

Figure 16 Mean bubble diameter vs. mean void fraction for propane, iso-butane and n-pentane in boiling conditions. This figure shows the importance of tube clearance for the organization of the flow regime.

Figure 17 Sketch of the two flow regimes proposed for boiling conditions outside a tube bundle. (a) Bubbly flow. (b) Annular-Dispersed f low. 
Figure 18 Flow regime map for a staggered tube bundle in hydrocarbon flow boiling conditions. The two vertical lines represent transitions between the flow regimes (bubbly flow for $\mathrm{j}_{\mathrm{G}}<0.15 \pm 0.03 \mathrm{~m} . \mathrm{s}^{-1}$, annular-dispersed flow for $\mathrm{j}_{\mathrm{G}}>0.56 \pm 0.03 \mathrm{~m} . \mathrm{s}^{-1}$ and intermittent flow for $0.15 \pm 0.03<\mathrm{j}_{\mathrm{G}}<0.56 \pm 0.03 \mathrm{~m} . \mathrm{s}^{-}$ $\left.{ }^{1}\right)$. The dashed lines represent the transitions obtained by Noghrehkar et al. (1999) with adiabatic results.

Table 1 Physical properties of n-pentane, propane and iso-butane for the operating conditions used in the present investigation. The physical properties have been calculated at saturation temperature with REFPROP 6.01 software.

Table 2 Operating conditions for the three hydrocarbons used in the present investigation. A broad range of the operating conditions is covered. This constitutes a unique database of flow boiling in a tube bundle. 


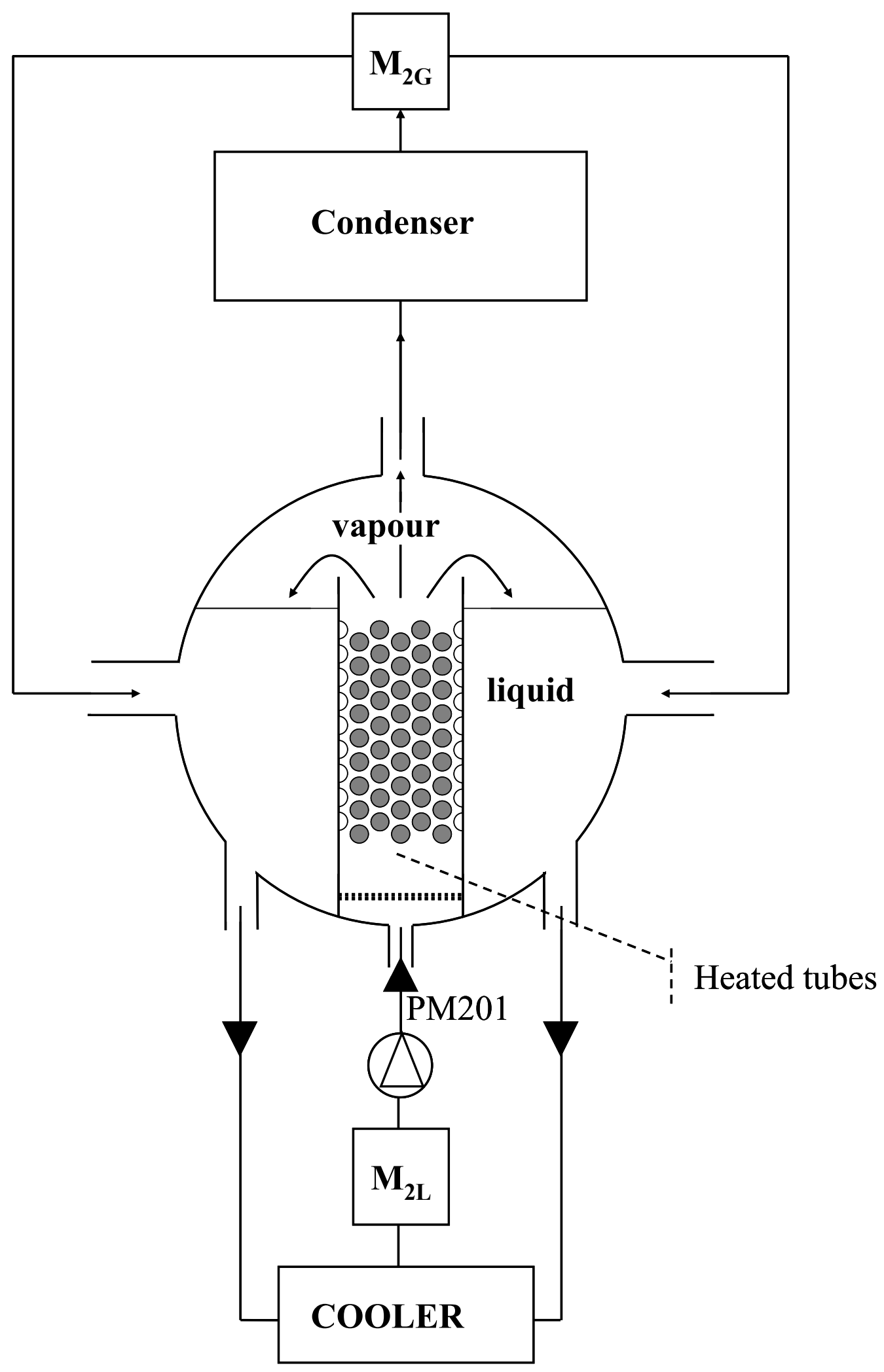

Figure 1 


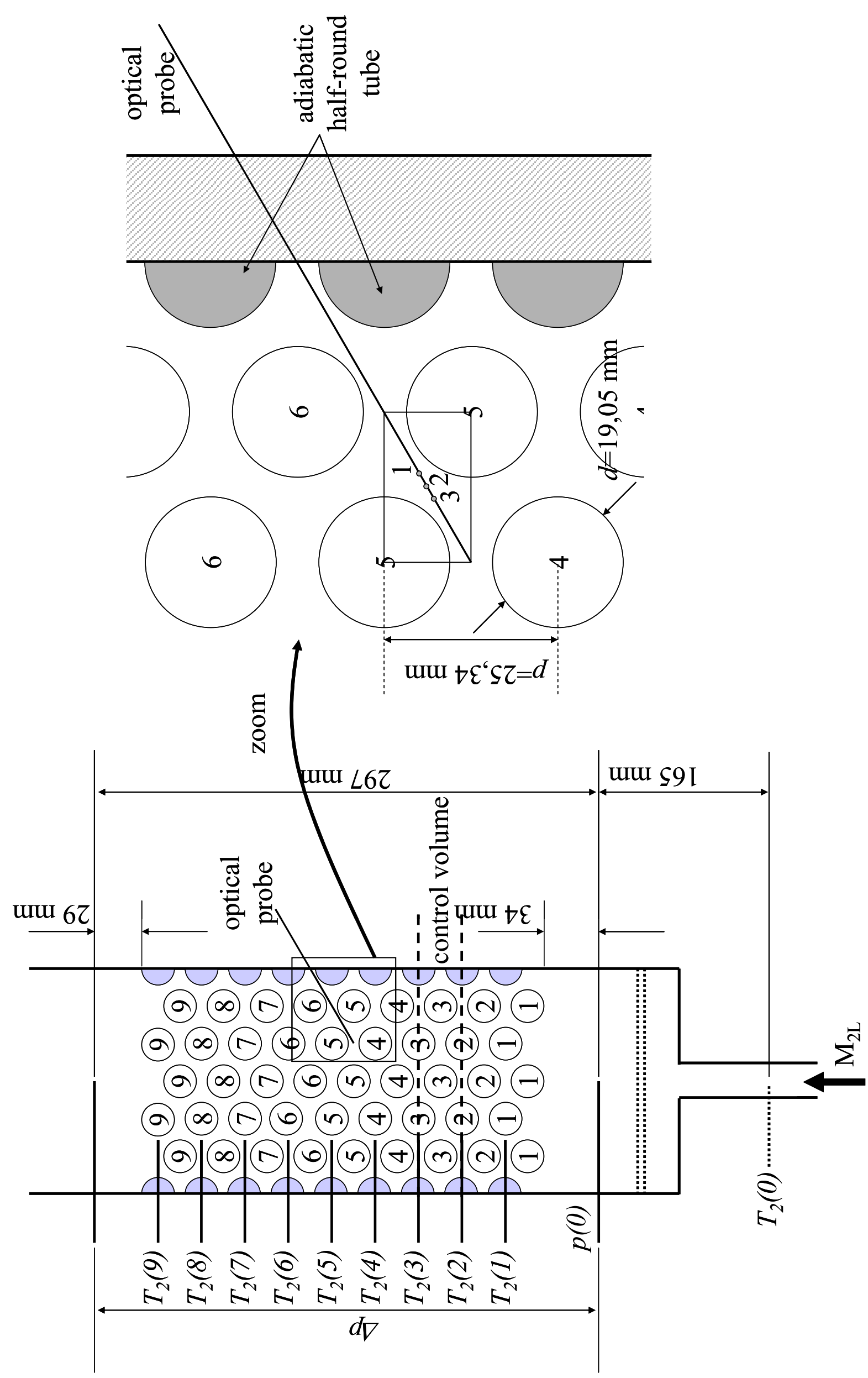

$\hat{e}$

Figure 2 


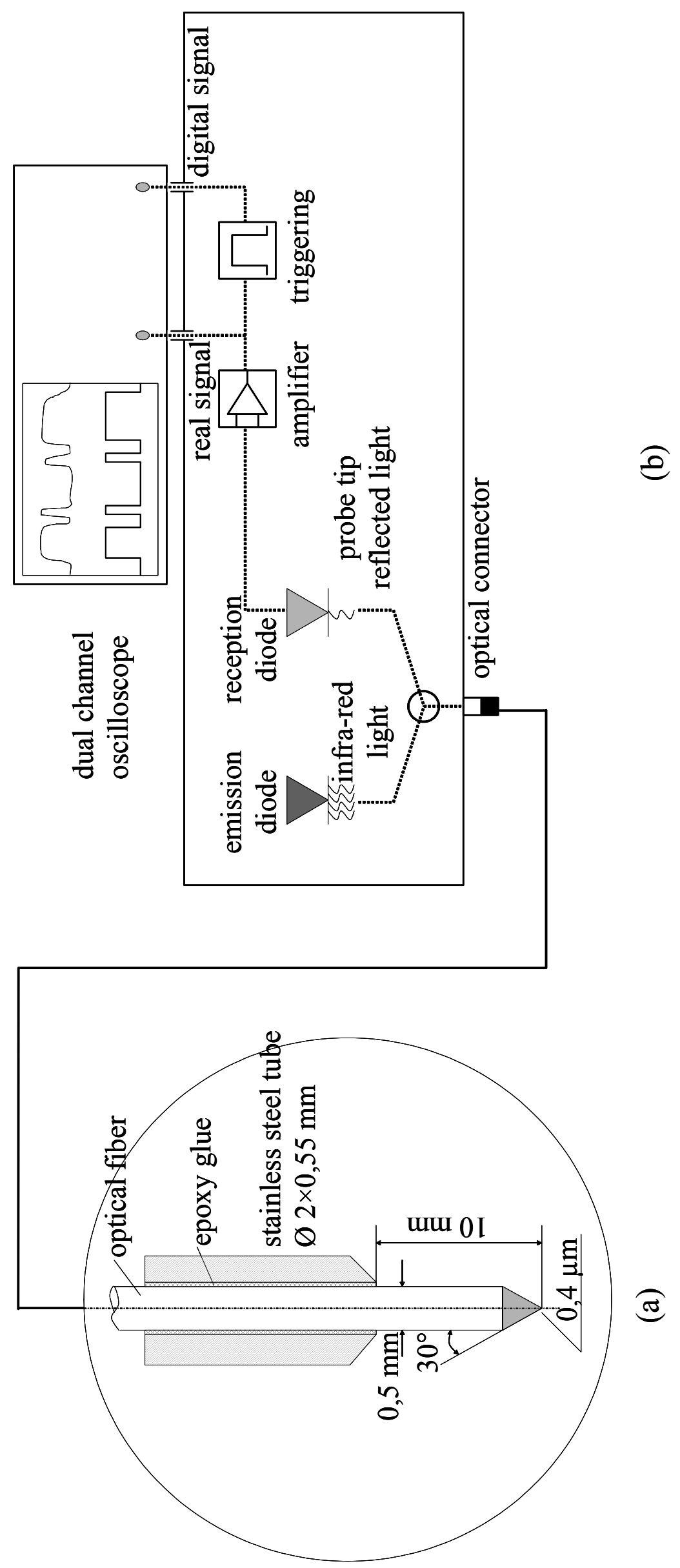

Figure 3 


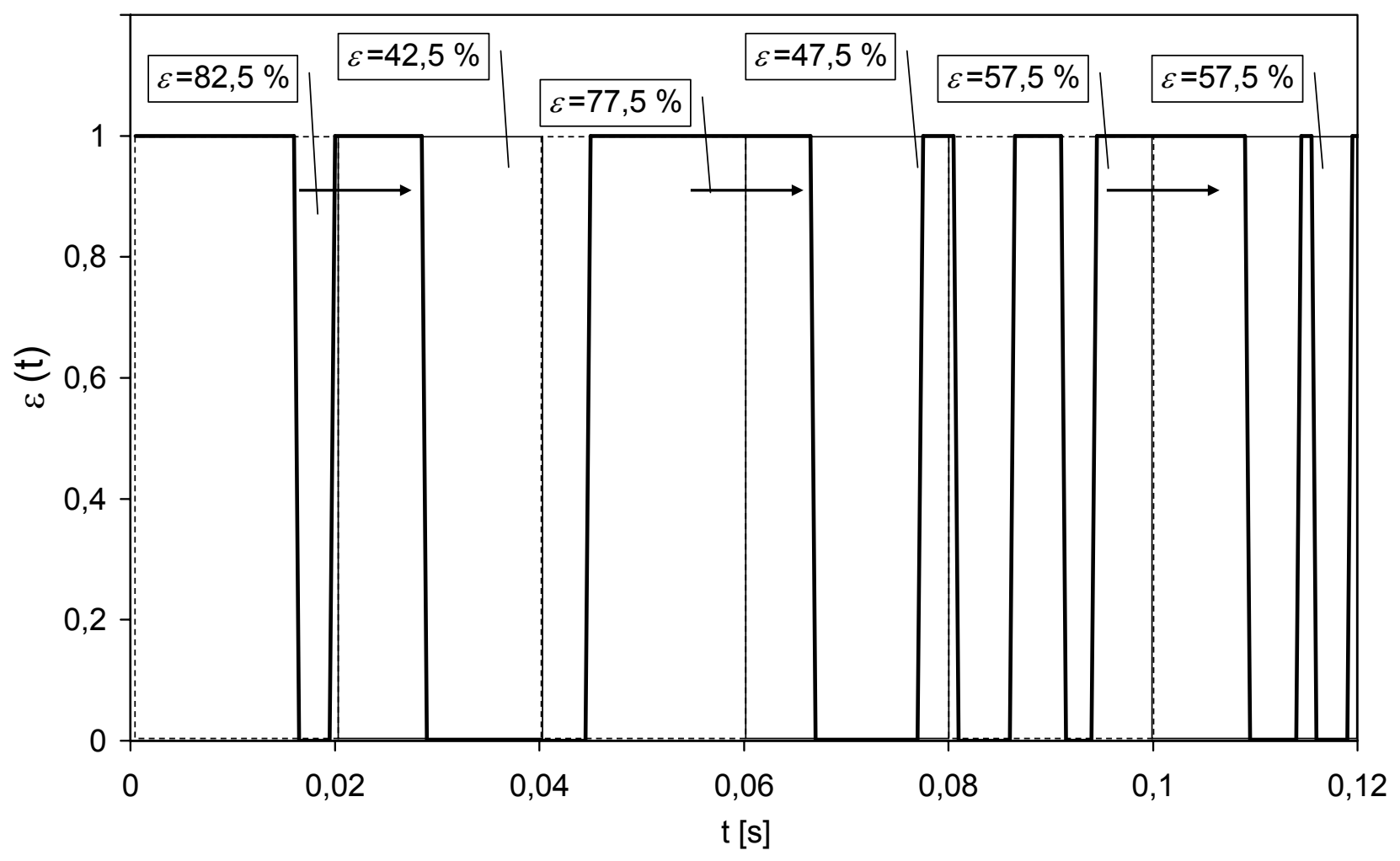

Figure 4 

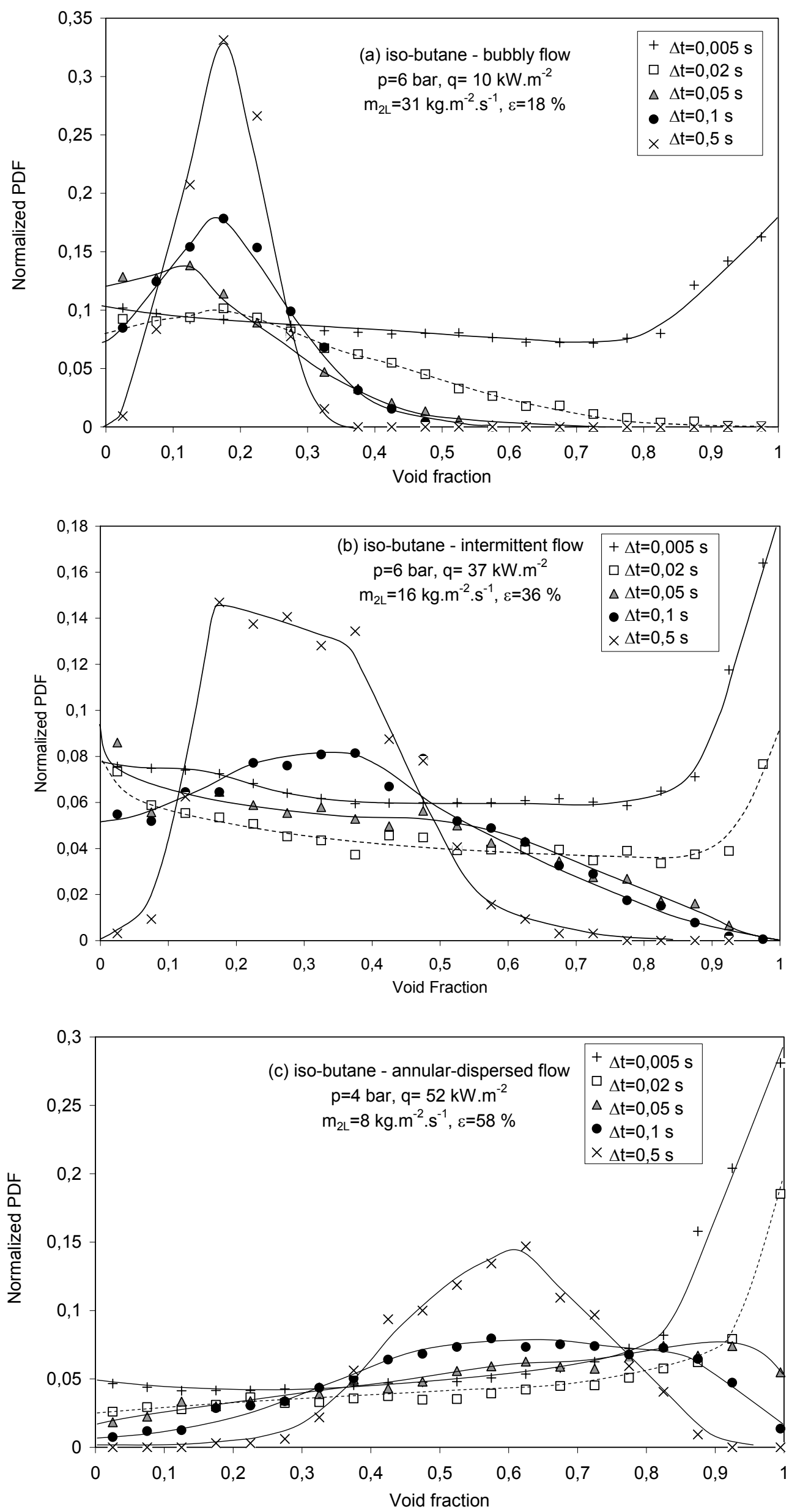

Figure 5 


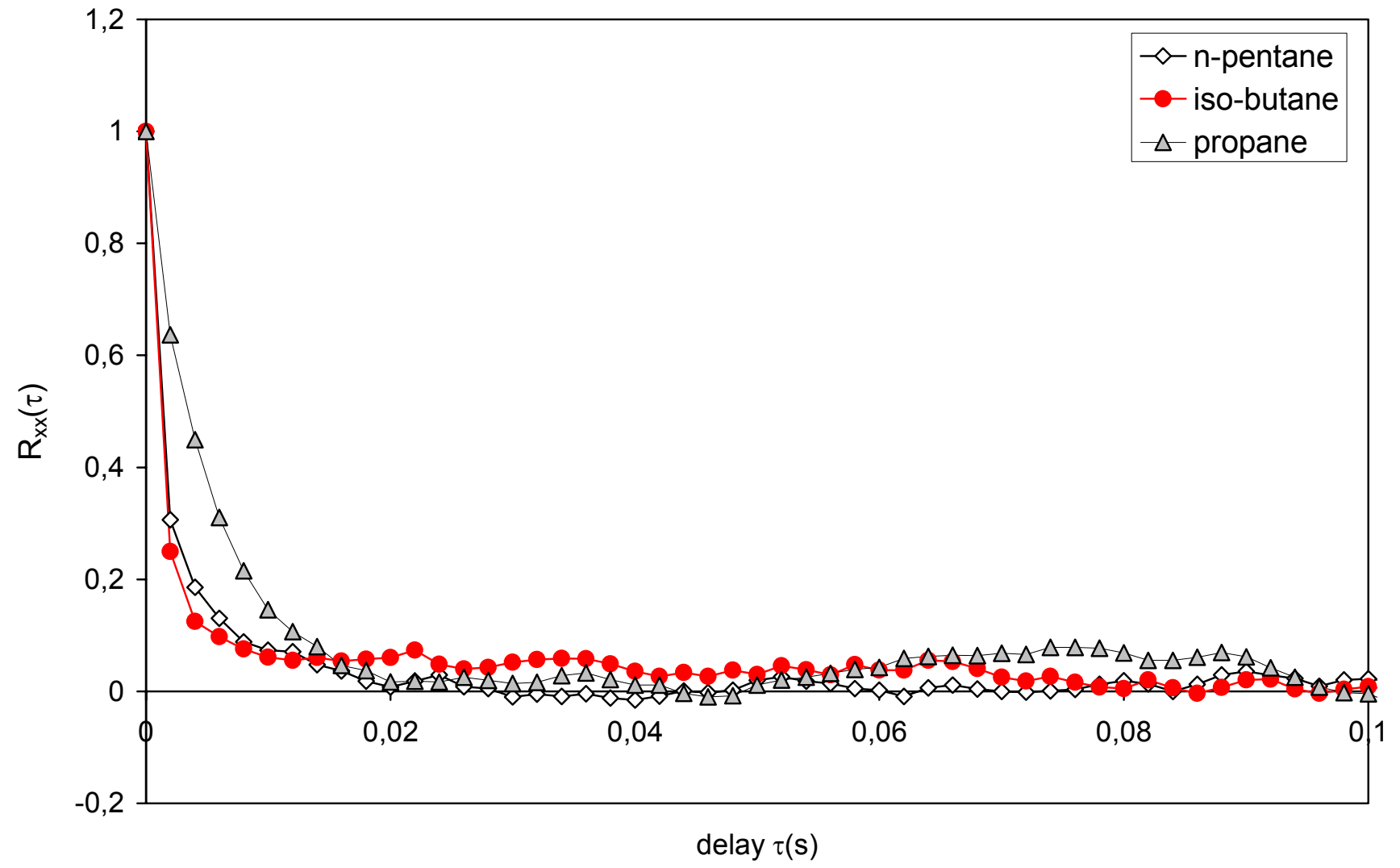

Figure 6 
a) $C_{M 3}>0$

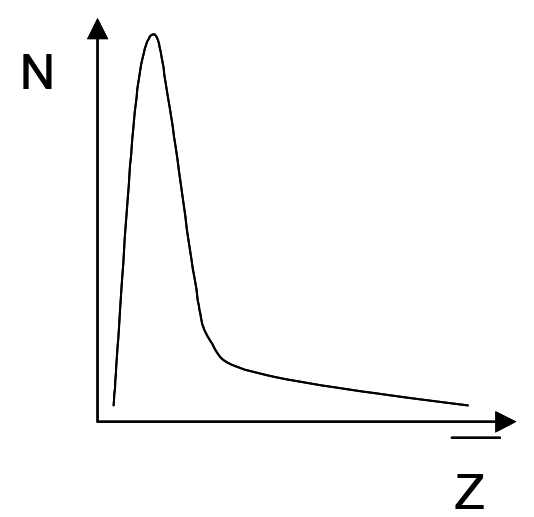

b) $C_{M 3}=0$

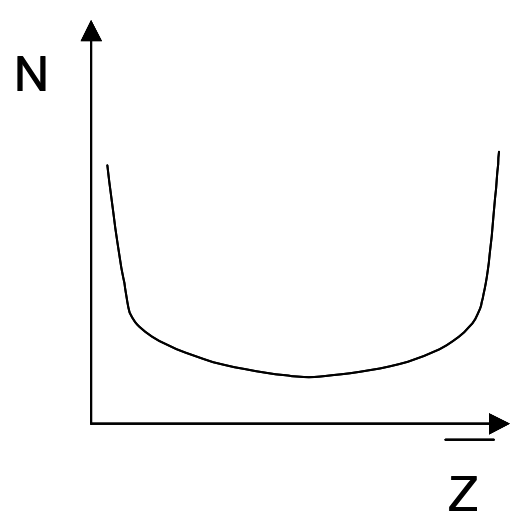

Figure 7 c) $C_{M 3}<0$

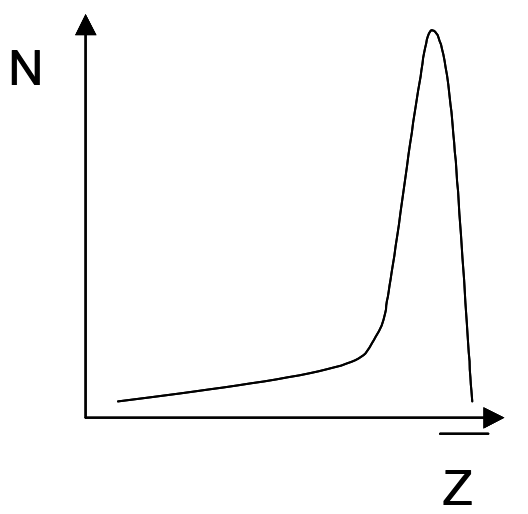


a) $C_{M 4}>3$

b) $C_{M 4}=3$

c) $C_{M 4}<3$
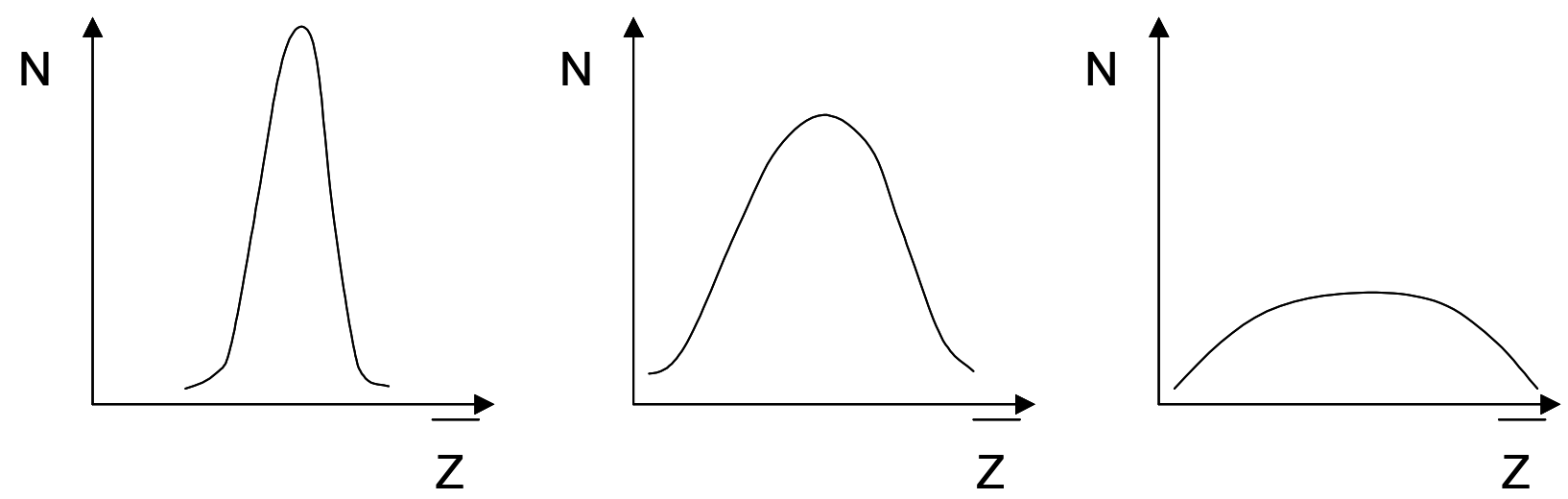

Figure 8 


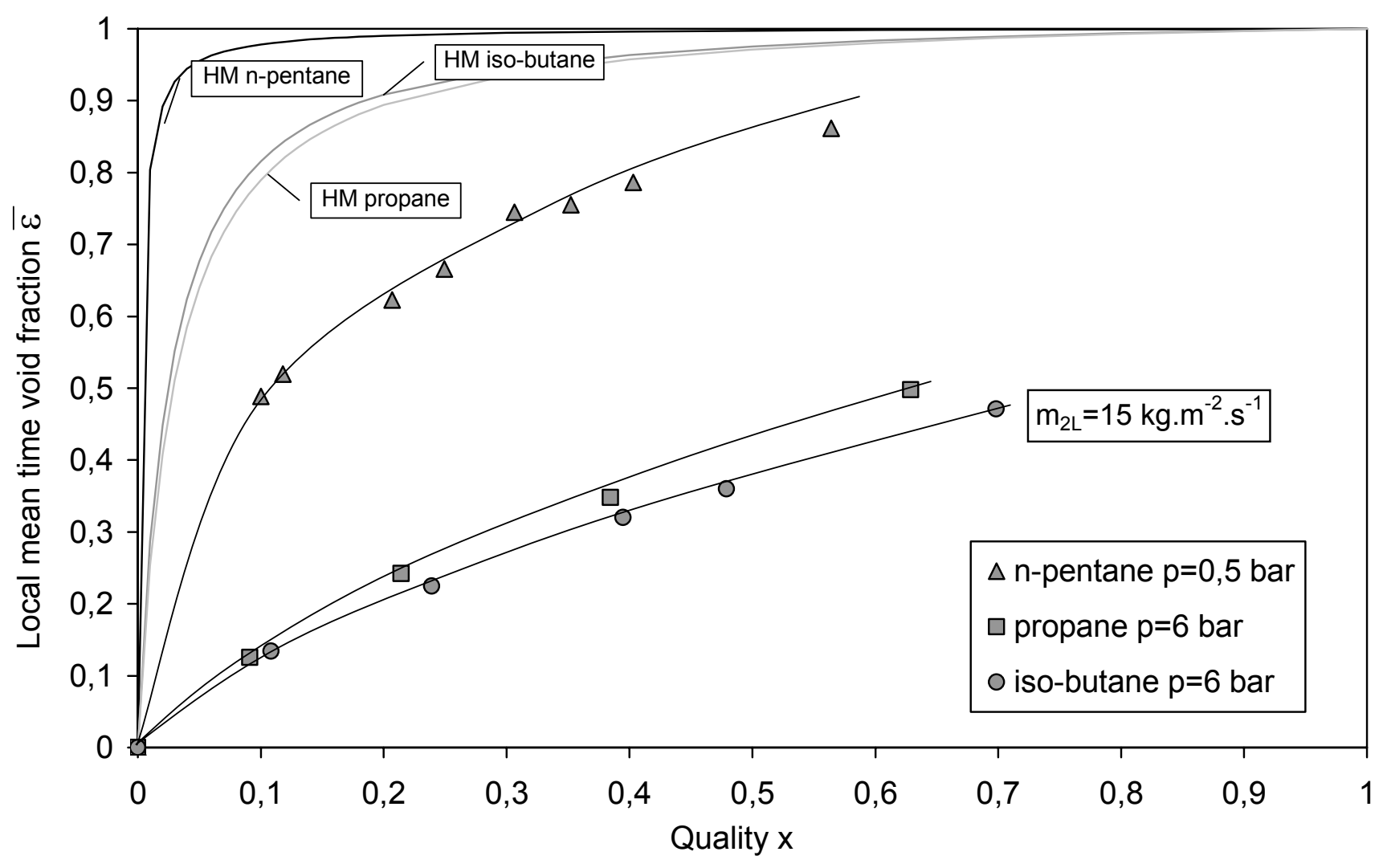

Figure 9 


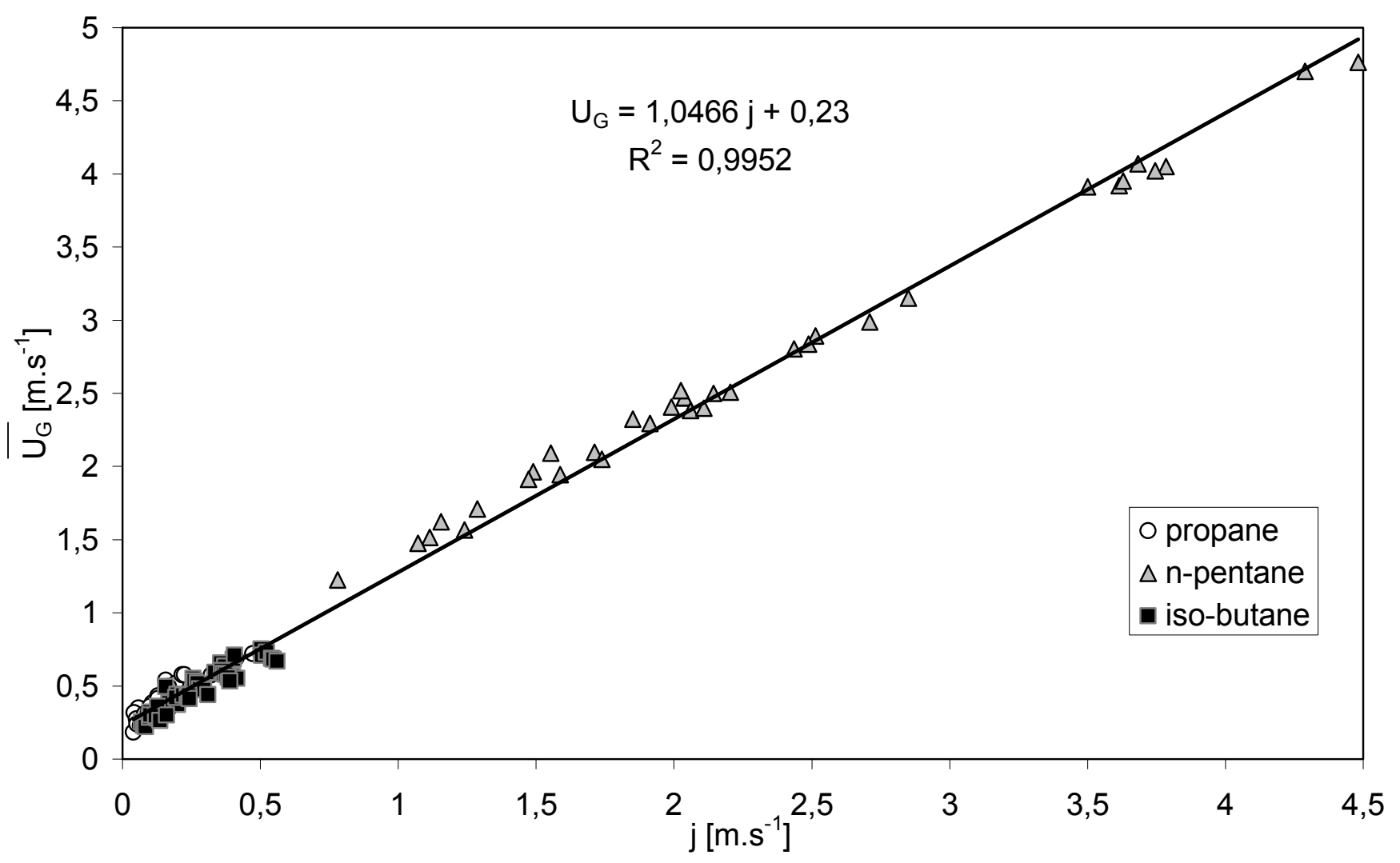

Figure 10 

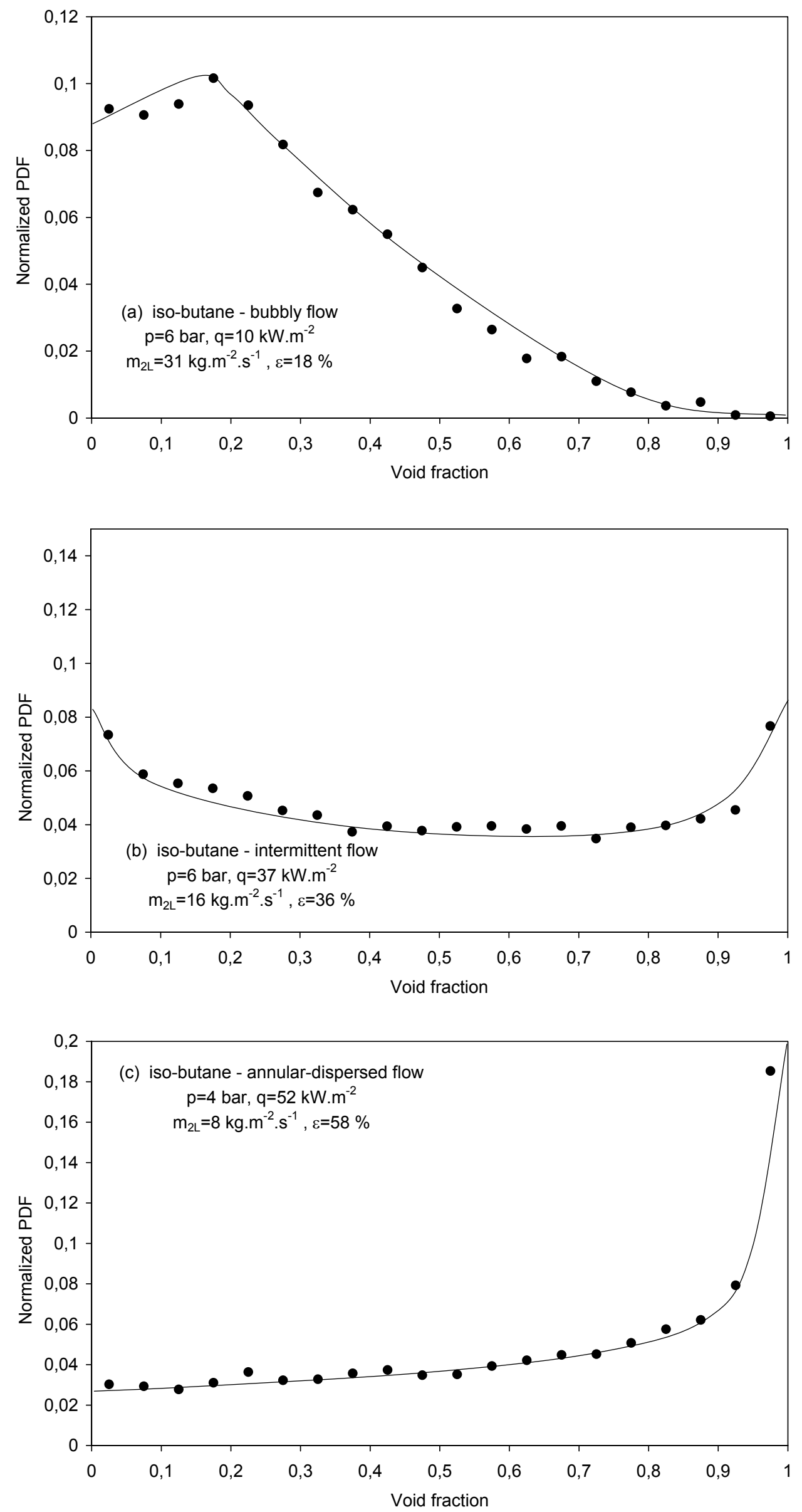

Figure 11 

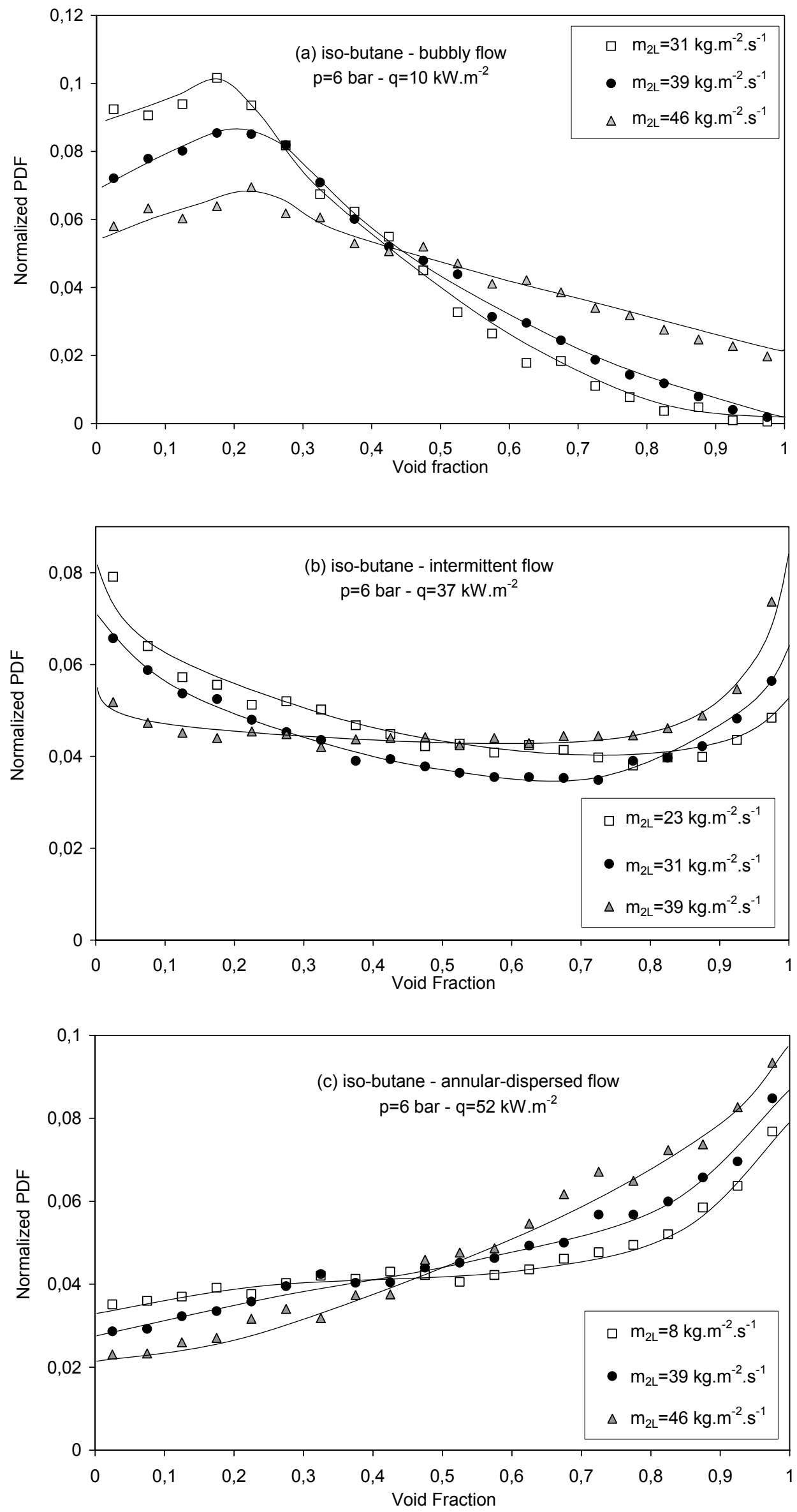

Figure 12 


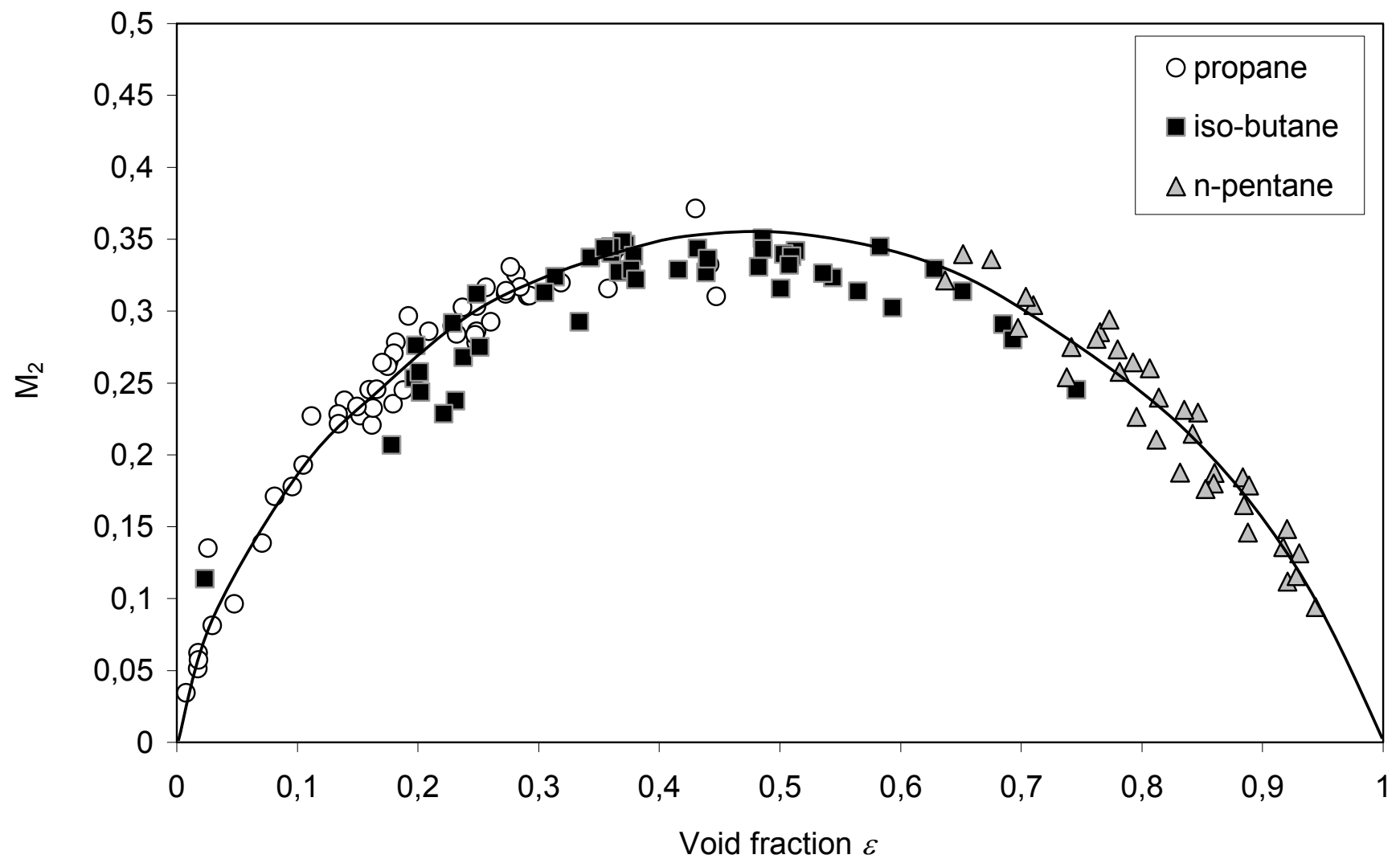

Figure 13 


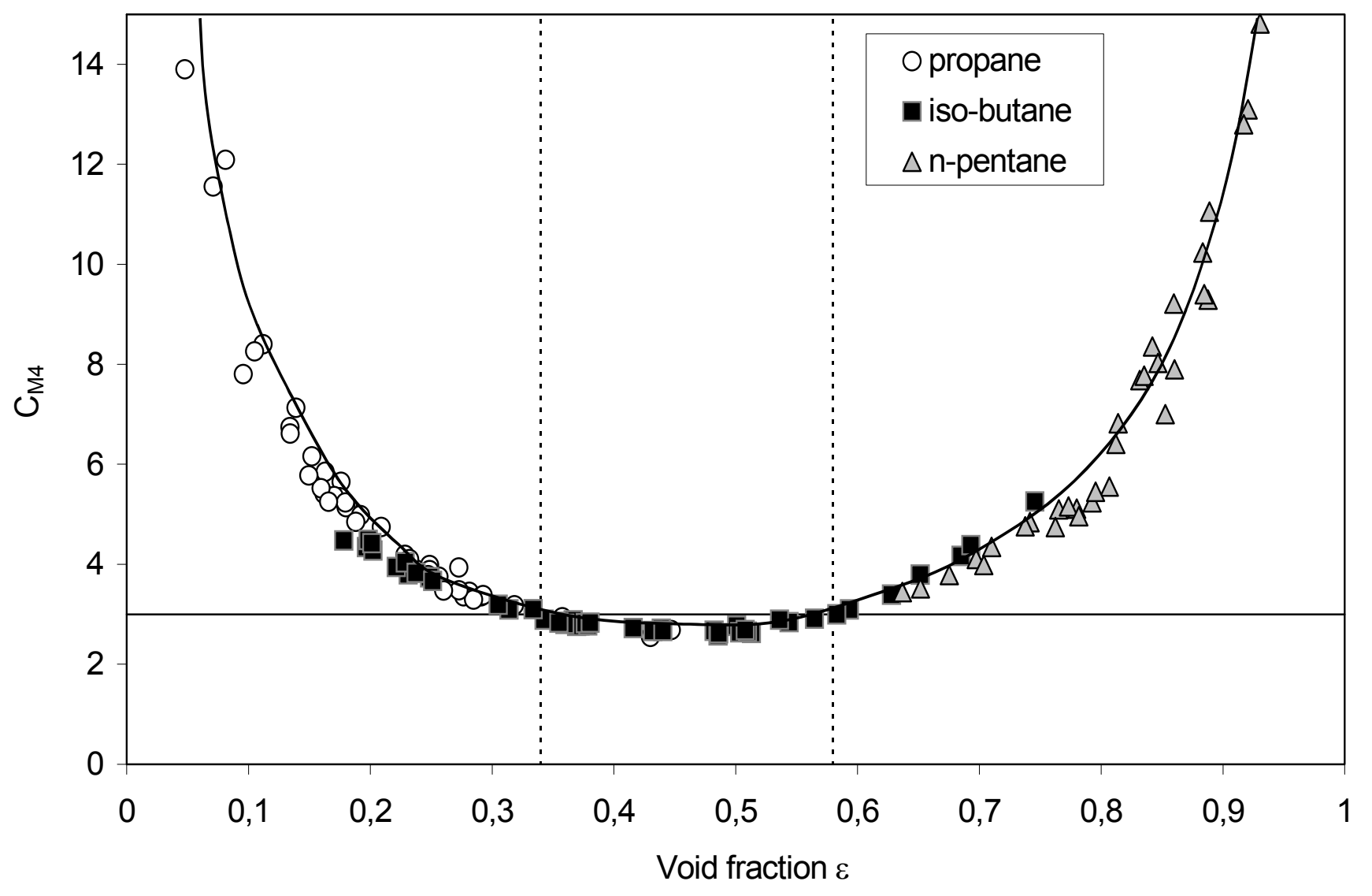

Figure 14 


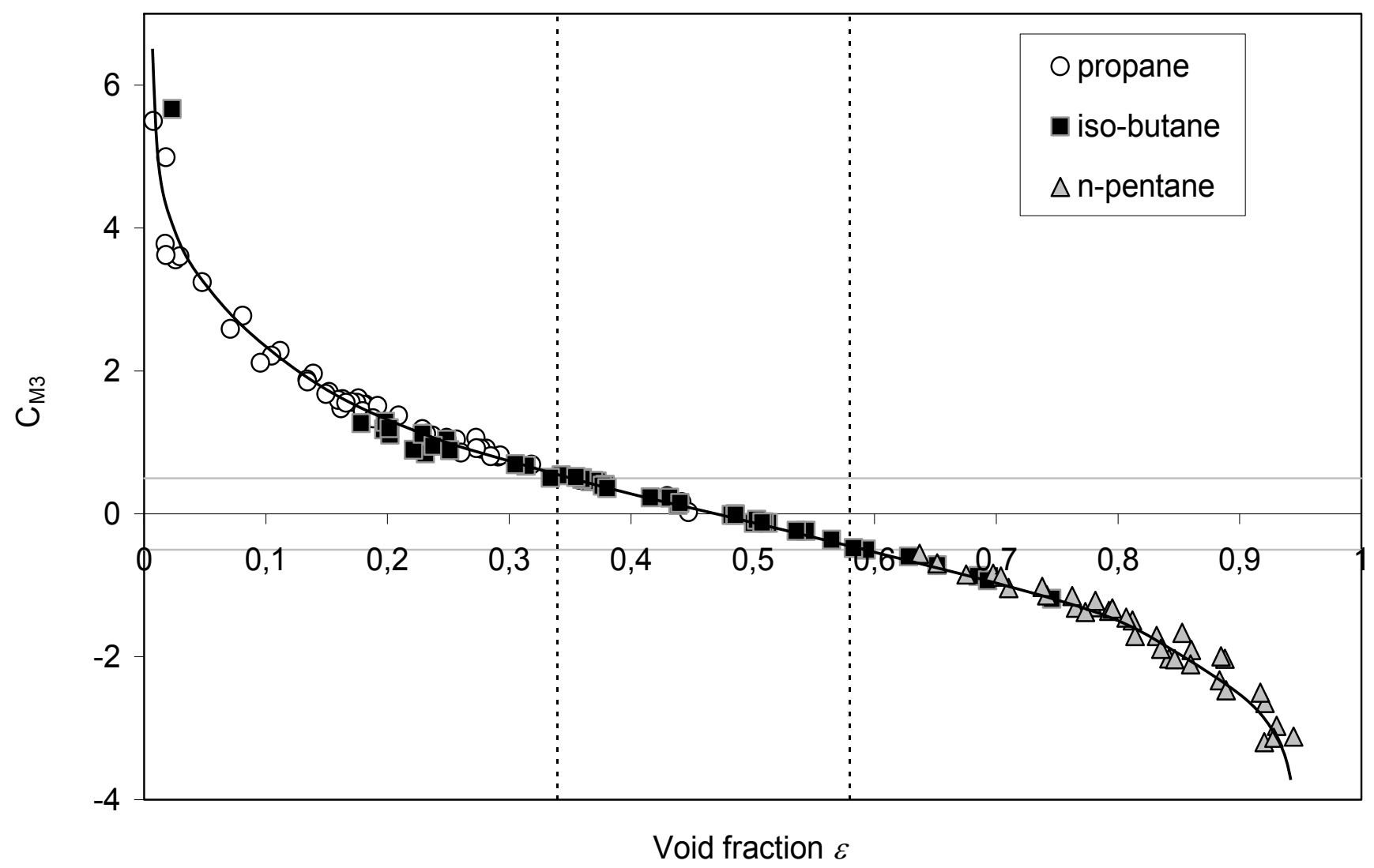

Figure 15 


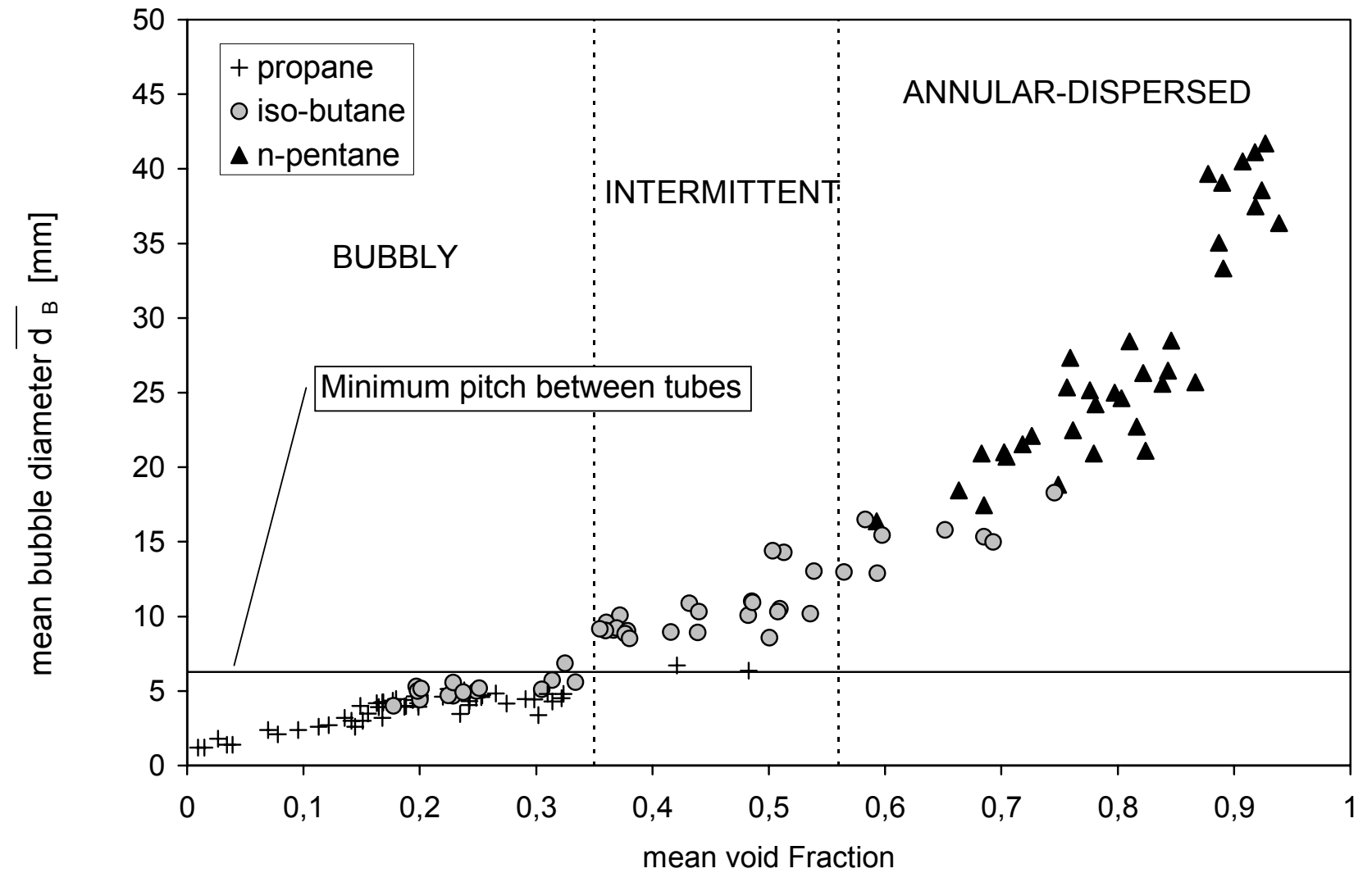

Figure 16 

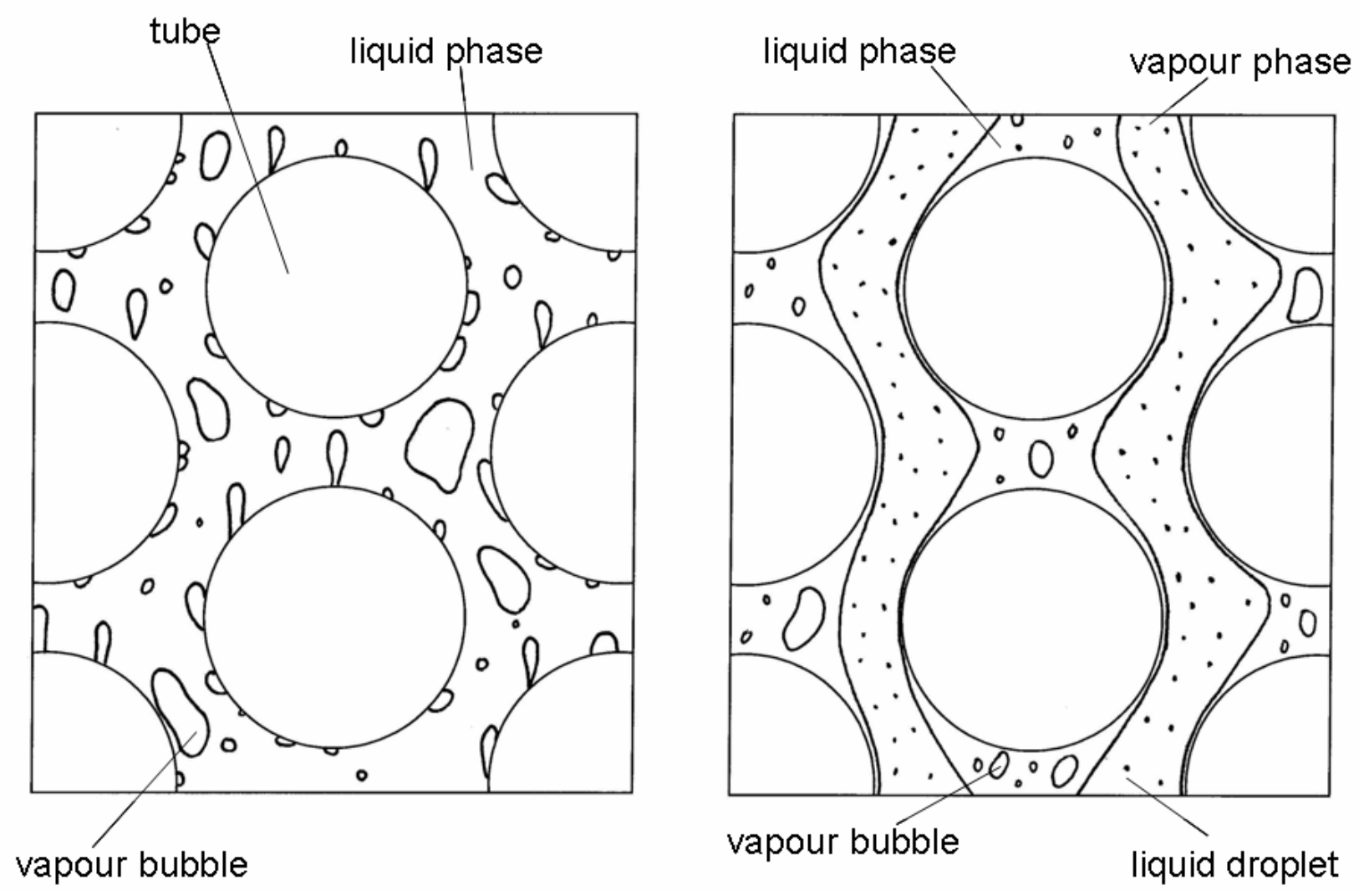

Figure 17 


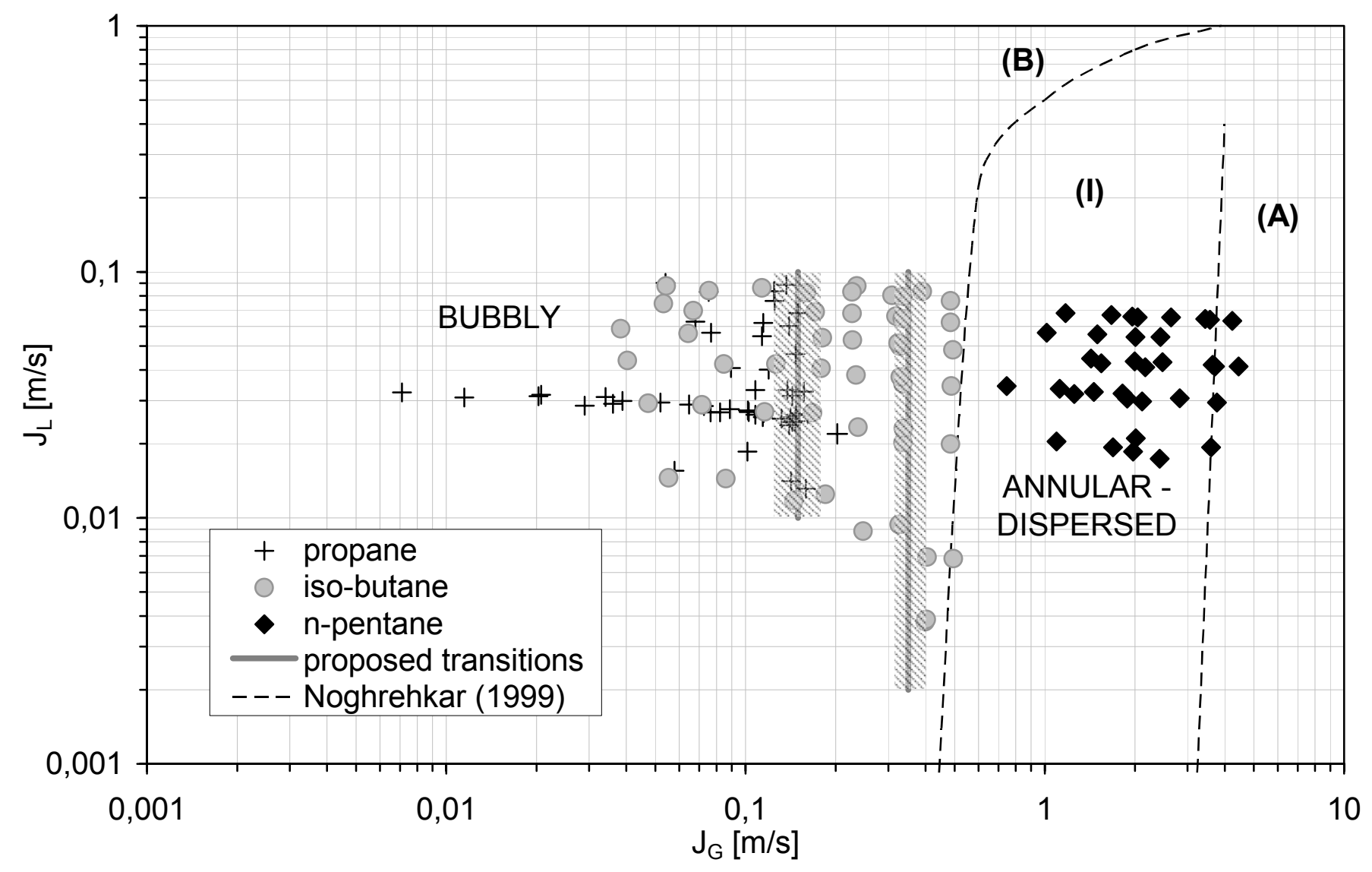

Figure 18 


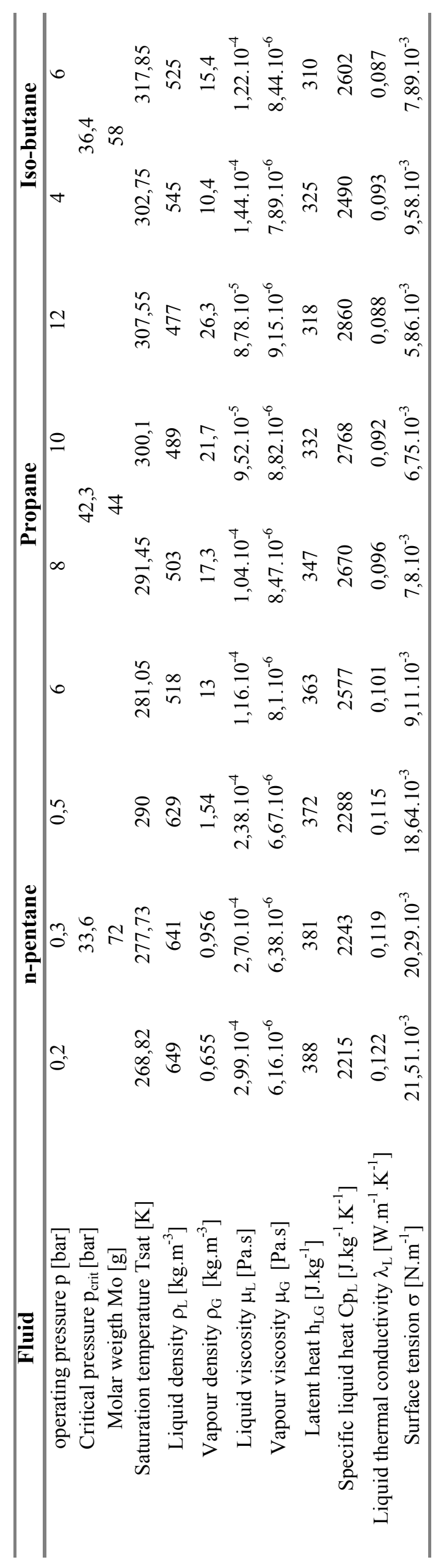

Table 1 


\begin{tabular}{cccc}
\hline & $n$-pentane & propane & iso-butane \\
\hline pressure $p[\mathrm{bar}]$ & $0,2 \leq p \leq 0,5$ & $6 \leq p \leq 12$ & $4 \leq p \leq 6$ \\
mass velocity $m_{2 L}\left[\mathrm{~kg} \cdot \mathrm{m}^{-2} \cdot \mathrm{s}^{-1}\right]$ & $15 \leq m_{2 L} \leq 44$ & $9 \leq m_{2 L} \leq 45$ & $8 \leq m_{2 L} \leq 44$ \\
heat flux $q\left[\mathrm{~kW} \cdot \mathrm{m}^{-2}\right]$ & $13 \leq q \leq 44$ & $3 \leq q \leq 53$ & $10 \leq q \leq 52$ \\
\hline
\end{tabular}

Table 2 